\title{
A NEW MECHANISTIC SCALE-UP METHODOLOGY FOR GAS-SOLID SPOUTED BEDS
}

\author{
Shreekanta Aradhya, Haidar Taofeeq and Muthanna Al-Dahhan* \\ Department of Chemical \& Biochemical Engineering \\ Missouri University of Science \& Technology, Rolla, MO - 65409, USA
}

\begin{abstract}
A new mechanistic methodology of scale-up for gas-solid spouted beds has been proposed and validated which is based on maintaining similar radial profiles of gas holdup. Two spouted beds of $0.152 \mathrm{~m}$ and $0.076 \mathrm{~m}$ inside diameter have been used. The local measurements of the dimensionless solids velocity and holdups using an advanced optical fiber probe and pressure fluctuations using pressure transducers indicate clearly the similarity when the radial profiles of the gas holdups were kept similar in the two studied spouted beds. When the radial profiles of the gas holdups were different in the two studied spouted beds, the dimensionless of the local studied parameters mentioned above were different. The differences increase when the difference in the magnitudes and trends of the gas holdup profiles increases.
\end{abstract}

Keywords: New scale-up methodology, Gas-solid spouted Bed, Solids velocity, Gas holdup radial profiles.

* Corresponding Author: aldahhanm@mst.edu

Tel: +1-573-578-8973, Fax: +1-573-341-4377 


\section{INTRODUCTION}

In gas-solid spouted beds the gas phase enters from the bottom as a jet and penetrates the bed of solid particles, which they are carried by the gas forming spout region (gas-solid riser). The gas carrying the solids, reaches the top of the bed surface forming a fountain region at the top, where the solids disengage from the gas phase. The solids then fall back onto the bed surface of the annulus region due to gravity. Hence, this nature of the spouted bed creates three distinctive regions or zones of: spout, annulus and the fountain. Spouted beds have found applications in many industrial processes, such as coating, pyrolysis, granulation, drying, coal combustion, gasification and cleaning, combustion and gasification of different wastes (plastics, biomass, tires, sewage sludge and others) and catalytic reactions. Recently, the gas-solid spouted beds have been used for manufacturing of TRISO nuclear fuel particles for the $4^{\text {th }}$ generation nuclear reactors.

The solids and gas interactions in gas-solid spouted beds are complex and therefore, there is a lack of understanding of the interplay phenomena of their hydrodynamics. Hence, the proposed methodology in the literature for their scale-up based on matching various dimensionless groups. For example, He et al. [1] proposed the following set of dimensionless groups based on the work of Glicksman [2]: $\left(\frac{g d_{p}}{u^{2}}, \frac{\rho_{s} d_{p} u}{\mu}, \frac{\rho_{s}}{\rho_{f}}, \frac{H}{d_{p}}, \frac{D_{c}}{d_{p}}\right.$, sphericity of particles $\left(\phi_{\mathrm{s}}\right)$, interfacial angle of particle $(\varphi)$, loose packed voidage $\left.\left(\varepsilon_{0}\right)\right)$ [1] and [2]. This method of scale-up has been only validated by measuring the global parameters such as spout diameter, dimensionless height, fountain height, pressure along the bed height, etc. However, when the local parameters were measured such as local solids velocity and holdup as per the work of [3] 
and [4], the methodology of scale-up of matching the proposed dimensionless groups was clearly not adequate to maintain hydrodynamics similarity. This indicates the needs to match more dimensionless groups to capture the missing interplaying phenomena which will complicate the implementation of such method for scale-up since it is not easy to match a large number of dimensionless groups.

Another approach that has been used and studied in the literature is the utilization of the draft tube in 3-dimensional (3D) and parallel plates in 2-dimensional (2D) gas-solid spouted beds with the diameter of the draft tube or the space between the two plates equal to the diameter of the nozzle or the gas injection opening [5], [6] and [7]. This helps structuring the circulation of the solids through the draft tube or the parallel plates spacing which acts as the spout region in a form of a riser for the solids and the gas phase inside the draft tube and the space between the parallel plates for the 2D gas-solid spouted beds. The solids disengage from the gas phase at the fountain and fall onto the annulus region which recirculate back from the annulus region to the draft tube or the parallel plates spacing through the gap at the bottom between the draft tube or the plates and the cone wall of the spouted bed. Although this defined structure would help the process of scaling up for the hydrodynamics similarity of the gas-solid spouted beds, it reduces one of their characteristics which is the supplying of the solid particles to the spout region along its height. For the spout region in the spouted beds without draft tube or parallel plates, the solids holdup increases due to their supply from the annulus region and hence the solids velocity decreases along the height of the spout region [8] and [9]. While this structure of the solids flow and the gas phase interaction with the solid particles complicate the flow dynamics of the spouted bed, it benefits the performance of these contactors as coaters (e.g. manufacturing of 
TRISO nuclear fuel particles for the $4^{\text {th }}$ generation nuclear reactors), dryers, granulators, gasifiers, combustors, etc. Therefore, in this work we propose and validate a new mechanistic scale-up methodology for gas-solid spouted beds as outlined below using sophisticated optical fiber probe technique for local hydrodynamics measurements and pressure transducers.

\section{THE NEW SALE-UP METHODOLOGY}

It has been found that the gas phase dictates the flow dynamics of the gas-solid spouted beds [3], [4] and [11]. Therefore, we propose a new mechanistic scale-up methodology which is based on the following: "the radial profiles of the gas holdup should be the same or close to each other particularly in the spout region for the two different spouted beds that are geometrically similar in order to maintain the hydrodynamics similarity or close to each other in these two different spouted beds" [8], [10] and [11].

The hydrodynamics similarity means either the magnitudes or the dimensionless representations of the hydrodynamic parameters (holdups, velocity, turbulent parameters, etc.) are the same or close to each other. The dimensionless representations can be used as a scaling criterion to estimate the actual magnitudes of the hydrodynamic parameters at different conditions or different dimensions (scales) based on the measured dimensionless magnitudes and profiles measured for the based conditions and/or dimensions [11] and [12].

In the present work, we evaluate for the purpose of validating the proposed new scale-up methodology using sophisticated optical fiber probe technique that measures simultaneously solids velocity and holdup and their time series, and pressure transducers that measure pressure 
signal at the wall. The conditions that provide similar and non-similar radial profiles of gas holdups in spouted beds were identified and utilized. The conditions for non-similar radial profiles of gas holdup have been used to demonstrate that when the radial profiles of the gas holdup are different, the hydrodynamics are different and the magnitude of the differences are proportional to the magnitude and trend of the differences in the gas holdup radial profiles [8] and [11]. Thus, extensive experimental work has been performed to select these sets of conditions and dimensions. As the first step, validated CFD code and closures [8] and [13] was used as an enabling tool for implementing this new scale-up methodology to identify the range of conditions and dimensions that would provide similar and non-similar radial profiles of gas holdup in the studied two spouted beds. Then the optical fiber probe was used to measure the radial profiles of the gas holdup at these identified conditions and dimensions to check whether these gas holdup radial profiles are similar and non-similar. Many measurements were made at refining conditions within the range of the conditions selected from CFD simulations to ensure the similarity in the radial profiles of the gas holdup [13].

The new mechanistic methodology of scale-up for gas-solid spouted beds can be extrapolate to industrial scales and conditions. Therefore, to implement this new mechanistic method of scale-up of gas-solid spouted beds in research or in industrial practice, the following steps should be taken:

1- Implementing validated CFD as an enabling tool to identify the conditions in a gas-solid spouted bed of desired dimensions (scales) and/or conditions including industrial dimensions and that provide closer or similar radial profiles of gas holdups with respect to the based 
conditions and dimensions of the studied laboratory, a cold flow unit, or a pilot plant scale gas-solid spouted bed.

2- Designing, developing and operating the gas-solid spouted bed at the defined conditions and dimensions of Step 1.

3- Implementing gamma ray densitometry (GRD) as an on-line monitoring technique to measure the radial profiles of the gas holdup [3] and [11], which is currently used in industry as a nuclear gauge densitometry for level measurements and control.

4- Refining the operating conditions, if needed, to make the radial profile of the gas holdup in the developed gas-solid spouted bed as closer as possible to that of the spouted bed with the based conditions and dimensions.

5- Reassessing the validation of the CFD and modifying the closures, if needed, to simulate properly the newly obtained radial profile of the gas holdup at the refined conditions of the developed gas-solid spouted bed obtained in Step 4.

6- Utilizing both the on-line monitoring GRD technique and the validation CFD to monitor with time the performance and operation of the developed gas-solid spouted bed to continue ensuring the hydrodynamics similarity and the desired performance with respect to that of the spouted bed with the based conditions and dimensions.

\section{EXPERIMENTAL SET-UP}

Two spouted beds were selected from the four spouted beds used by He et al. [1] in the present study of inside diameter $0.152 \mathrm{~m}$ and $0.076 \mathrm{~m}$ where the spouted bed of $0.152 \mathrm{~m}$ in diameter was selected for the base or reference condition. The schematic diagrams of these 
spouted beds with detailed dimensions of $0.152 \mathrm{~m}$ and $0.076 \mathrm{~m}$ spouted bed are shown in Figure 1. The spouted bed columns are constructed from Plexiglas and consist of one-piece column attached to a conical base of $60^{\circ}$ degree. Having a one piece column will improve the symmetry of the column and help stabilize the fountain. The $0.152 \mathrm{~m}$ column is $1.016 \mathrm{~m}$ tall, with a total of thirty-five measurement ports of $0.0127 \mathrm{~m}$ diameter spaced every $0.0508 \mathrm{~m}$ on both front and back so that axial measurements can be made at separations of $0.0254 \mathrm{~m}$. To further measure the symmetry of the annulus, axial measurement ports are located on all sides of the column (90 degree separation) every $0.152 \mathrm{~m}$ from the bottom $0.3048 \mathrm{~m}$ of the column. That gives the ability to measure the dynamics of the spout and annulus without crossing and disrupting the spout with the probe. The column sits at the top of a Plexiglas cone base, with two measurement ports in order to measure the dynamics and concentration of the spout near the air inlet. The cone is angled at 60 degree and the gas inlet orifice for the gas jet is $0.019 \mathrm{~m}$ in diameter. A sliding distributor system is used, that will allow the use of multiple high open area distributor designs for the gas jet to be created and also allow the assessment of the effects of different sizes of gas inlet jets on the spout and fountain. The $0.076 \mathrm{~m}$ diameter spouted bed very closely resembles the $0.152 \mathrm{~m}$ spouted bed with overall height of $0.9144 \mathrm{~m}$. The $0.076 \mathrm{~m}$ spouted bed also has axial measurement ports every $0.0508 \mathrm{~m}$ on both sides in order to take axial measurements at 0.0254 $\mathrm{m}$ increments along the whole column. Measurements to deduce symmetry is possible due to the inclusion of ports on all four sides of the column at $0.076 \mathrm{~m}$ increments from the bottom 0.3048 $\mathrm{m}$. The cone for the $0.076 \mathrm{~m}$ diameter spouted bed is also angled at 60 degree and is fitted with a sliding distributor design like that of the $0.152 \mathrm{~m}$ diameter spouted bed. 


\section{MEASUREMENT TECHNIQUES}

\subsection{Gas-solids optical fiber probe}

Advanced optical fiber probe (Figure 2), which was acquired from the Institute of Process Engineering of the Chinese Academy of Sciences has been used in this work to measure local solids velocity, holdup and their time series and also the spout diameter. The probe works on the principle of the back reflection of light. It consists of two separate bundles of optical fibers. Each bundle consists of small optical fibers arranged in alternate fashion. The dimension of the bundle is $2.0 \times 2.0 \mathrm{~mm}$. The probe had two small tips protruding from the face of the probe. These tips are $5 \mathrm{~mm}$ in diameter and at a distance of $4.15 \mathrm{~mm}$ from each other. The two separate optical bundles have separate channels for signal processing. The design has defined measuring volume allowing for the measurement of solids concentration related signal. The two probe tips provide two separate signals, which can be analyzed by cross-correlation to obtain particles velocity. The voltage signals measured by the probe contain information about solids concentration. These voltage signals have been converted into solids volume fraction through the suitable calibration process available in our laboratory. More details about the calibration process can be found in $[8]$.

\subsection{Pressure transducer}

A pressure transducer for measuring gauge pressure and its time series signal (Omega Inc., Model. No. PX309-002G5V) has been used which is mounted at the wall region as shown 
in Figure 3. The data acquisition for the pressure transducer consists of an A/D converter, which converts the pressure fluctuations into electrical signals.

\section{SELECTION OF THE STUDIED CONDITIONS}

The key step to evaluate and validate our newly proposed scale-up methodology, is to identify the conditions that provide closer or similar gas holdup radial profiles between two different spouted beds and the conditions that provide non-similar gas holdup radial profiles. In this work extensive experimental work and CFD simulation have been made to search particularly for the conditions that provide the closest radial profiles of the gas phase holdups between the selected gas-solid spouted beds. The selection of the studied conditions was based on the following:

1. A reference spouted bed of $0.152 \mathrm{~m}$ (6 inches) diameter and the reference conditions of Case A listed in Table 1 were selected based on the work of He et al. [1]. He et al. [1] used many sets of conditions to evaluate the method of matching dimensionless groups for scaling up of gas-solid spouted beds. This selected reference case (Case A, Table 1) is similar to the reference case chosen by He et al. [1].

2. Case B of $0.076 \mathrm{~m}$ diameter spouted bed and the conditions that provide similar gas holdup radial profile to that of Case A were identified. We started with the case from He et al. [1] with closely matching dimensionless groups. The operating conditions (pressure and superficial gas velocity) were changed using CFD simulation to achieve similar gas holdup radial profile comparing with Case A.

3. Case $\mathrm{C}$ of $0.076 \mathrm{~m}$ diameter spouted bed and the conditions that provide non-similar gas 
holdup radial profile to that of Case A were selected from He et al. [1] which provide different values of dimensionless groups (mismatching dimensionless groups) in the work of He et al. [1].

Once the three cases have been identified, a comprehensive evaluation (radial profiles of gas and solids holdup, solids velocity, pressure fluctuations, spout diameters and fountain heights) have been performed using the optical fiber probe and the pressure transducer techniques to validate the proposed scale-up methodology. Table 1 shows these cases of the similarity and non-similarity in radial profiles of the gas phase. The emphasis here is to show that if one maintains similar or closer radial profiles of gas holdup, the flow dynamics of the two systems will be the same or closer to each other. Such a similarity in the flow dynamics of the system is the ultimate goal of any scale-up methodology in order to maintain the desired conversion and process performance.

\section{RESULTS AND DISCUSSION}

The statistical difference between evaluated parameters is represented in terms of the average relative difference which is defined as follows

$$
\text { Absolute Average Relative Difference }=\frac{1}{N} \sum_{1}^{N}\left[\frac{x(r)-y(r)}{x(r)}\right]
$$

Where, $\mathrm{x}$ and $\mathrm{y}$ can be local or global parameters at corresponding radial locations and $\mathrm{N}$ is the corresponding total number of data points. Since several parameters are evaluated for the 
conditions of similar and non-similar radial profiles of gas holdups $\left(\varepsilon_{\mathrm{g}, \mathrm{r}}\right)$ identified in Table 1 , each of them is discussed in separate sections below.

\subsection{Gas holdup profiles}

Gas holdup profiles measured for the two different sizes of the spouted beds using conditions for similar radial profiles of gas holdup are shown in Figure 4. The measurement levels compared are at z/D 1.1, 1.8 and 2.5 (fountain region). First, the solids holdup was measured using the optical fiber probe, and then the gas holdup was calculated $\left(\varepsilon_{\mathrm{g}}=1-\varepsilon_{\mathrm{s}}\right)$. The comparison of radial profiles of the gas holdup in both $0.152 \mathrm{~m}$ and $0.076 \mathrm{~m}$ spouted beds shows that the profiles were very close to each other. The absolute average relative difference between the two radial profiles was $4.1 \%$. This represents a close agreement of the newly defined conditions which are successfully able to match the radial profiles. In the scale-up approach of He et al. [1], the voidage in the annulus region was almost same, but differed drastically in the spout and fountain regions. Using the new conditions listed in Table 1, the profiles in the spout and annulus region were matched after numerous trials performed using CFD.

Gas holdup profiles were also measured for the conditions for non-similar radial profile of gas holdup to check the percentage of deviation between the two radial profiles. Figure 5 shows the radial profiles of gas holdup at $\mathrm{z} / \mathrm{D}$ levels of $1.1,1.8$ and 2.5 . It is observed that the deviations between the radial profiles were large in the spout region. In the annulus region, the deviations were very small as expected due to the downward movement of particles as a loose 
packed bed. The absolute average relative difference between the profiles was found to be $55.8 \%$ in the spout region.

\subsection{Solids velocity}

The solids velocity profiles of the beds were measured for the conditions of similarity and non-similarity in radial profiles of gas holdup listed in Table 1 with the use of the optical fiber probe technique. The details of the measurement of solids velocity using optical probe can be found in [8].

The solids velocity is high in the spout region as it is being picked up by the gas phase. The maximum velocity can be found in the center of spout region and the velocity reduces as it reaches the spout-annulus interface. The velocity in the annulus is very low and is negative including down ward flow. The solids move downwards in the annulus as a loose packed bed and hence, the velocity tends to be low. The particles velocity first increases near the inlet and then decreases as the height of the spouted bed increases. This means that the momentum imparted by the gas phase reduces as the height increases. In the fountain region, the center has the maximum velocity and as the radial distance increases toward the spout-annulus interface, the velocity of the solids decreases (Figures 6 and 7).

The comparison of the particles velocity profiles at different $\mathrm{z} / \mathrm{D}$ measurement levels for the conditions of similar and non-similar radial gas-holdup profiles is shown in Figures 6 and 7, 
respectively. The difference between the particles velocity profiles is maximum at the center of the spout and it decreases as it reaches the spout-annulus interface. The average percentage deviation for the particles velocity profiles for the conditions of similar radial gas holdup profiles at $\mathrm{z} / \mathrm{D} 1.1$ is $22.38 \%$. At $\mathrm{r} / \mathrm{R}=0$ (which is at the center of the column), the percentage deviation was found to be $47.61 \%$, at $r / R=0.1$ it was $33.36 \%$, at $r / R=0.2$ it was $28.57 \%$ and at $r / R=0.3$ it was $5 \%$. The average percentage deviation for the particles velocity profiles at $\mathrm{z} / \mathrm{D} 1.8$ is 19.54\%. At $\mathrm{r} / \mathrm{R}=0$ it was $35.82 \%$, at $\mathrm{r} / \mathrm{R}=0.1$ it was $30.06 \%$, at $\mathrm{r} / \mathrm{R}=0.2$ it was $23.33 \%$ and at $\mathrm{r} / \mathrm{R}=0.3$ it was $8.5 \%$. In the fountain region, the difference between the two profiles decreases until it reaches to $\mathrm{r} / \mathrm{R}$ of about $0.47-0.53$ and then the differences increase again. The average percentage deviation for the particles velocity profiles at z/D 1.8 is $20.77 \%$.

Figure 7 shows the particles velocity profiles for the conditions of non-similar radial profiles of gas holdup. The difference between the particles velocity profiles is lesser compared to the conditions of similar radial profiles of gas holdup. The average percentage deviation for the particles velocity profiles for the conditions of non-similar radial gas holdup at $\mathrm{z} / \mathrm{D} 1.1$ is $14.48 \%$. At $r / R=0$ (which is at the center of the column) the percentage deviation was found to be $34.21 \%$, at $\mathrm{r} / \mathrm{R}=0.1$ it was $20.21 \%$, at $\mathrm{r} / \mathrm{R}=0.2$ it was $11.18 \%$ and at $\mathrm{r} / \mathrm{R}=0.3$ it was $3.8 \%$. The average percentage deviation for the particles velocity profiles at $\mathrm{z} / \mathrm{D} 1.8$ is $16.11 \%$. At $\mathrm{r} / \mathrm{R}$ $=0$ it was $30.05 \%$, at $\mathrm{r} / \mathrm{R}=0.1$ it was $28.34 \%$, at $\mathrm{r} / \mathrm{R}=0.2$ it was $19.02 \%$ and at $\mathrm{r} / \mathrm{R}=0.3$ it was $3.31 \%$. In the fountain region, the difference between the two profiles decreases until it reaches to $\mathrm{r} / \mathrm{R}$ of about $0.51-0.57$ and then the differences increase again. The average percentage deviation for the particles velocity profiles at z/D 1.8 is $15.85 \%$. 
To have a common basis for comparison, the radial profiles were non-dimensionalized for both the spouted beds by dividing the values by the minimum spouting velocity $\left(\mathrm{U}_{\mathrm{ms}}\right)$. Where the minimum spouting velocity refers to the velocity at which the onset of spouting occurs and below this velocity there is no spouting in the bed. The gas was introduced into the spouted bed with very small increments. The velocity at which the spouting occurred was noted down as the minimum spouting velocity. The minimum spouting velocity for $0.152 \mathrm{~m}$ spouted bed was 1.04 $\mathrm{m} / \mathrm{s}$ and for $0.076 \mathrm{~m}$ spouted bed was $0.52 \mathrm{~m} / \mathrm{s}$. The measured $U_{\mathrm{ms}}$ values, were compared with the correlation predictions available in the literature [14] and [15]. Figure 8 shows the dimensionless particle velocity profiles for the two spouted beds at measurement levels of z/D 1.1, 1.8 and 2.5. The absolute average relative difference between the radial profiles was found to be $3.5 \%$. The closeness in the profiles was seen in all the three measured levels. The dimensionless particles velocity profiles for the conditions of non-similar radial profiles of the gas holdup were estimated and the results are shown in Figure 7. The absolute average relative difference in the profiles at the center was found to be $47.9 \%$. The observed deviations were in the spout region and the deviations in the annulus region were found to be very low or negligible. The velocity in the annulus is very low and is negative because solids move downwards in the annulus as a loose packed bed.

The difference in the magnitudes of the particles velocity profiles between the reference case and the case of similar radial profile of gas holdup was high. The reference case $(0.152 \mathrm{~m})$ uses glass beads $\left(2450 \mathrm{Kg} / \mathrm{m}^{3}\right)$ as the solids phase. In this case, the cross-sectional area of the spout region, gas velocity and the solids holdup is larger. Hence, the cross-sectional area of the solids to flow in the spout region is larger in the reference case. However, in the case of the 
similar radial profile of gas holdup using another bed of $0.076 \mathrm{~m}$ diameter, the solids phase is steel shots $\left(7500 \mathrm{Kg} / \mathrm{m}^{3}\right)$. In this case, the cross-sectional area of the spout region and the gas velocity are smaller that that of the refrence case, and the solids holdup is equal to that of the reference case. As a result, the cross-sectional area of solids to flow is smaller than that of the reference case. To understand the difference between the particles velocity profiles in the two beds even though the solids holdup values are the same needs more insight. Hence, drag force was evaluated from validated CFD [8] for both cases to see its effect on the particles velocity. In the spout region, the reference case $(0.152 \mathrm{~m})$ has a larger drag force on the particles compared to the case of similar radial profile of gas holdup which has smaller drag force acting on the particles (Figure 10.a and b). The gas phase is the driving force in the spouted bed as mentioned earlier as it dictate the hydrodynamics of the bed. The momentum from the gas phase is imparted to the solids phase which is transferred to the mean particles velocity, the components of the velocity and their fluctuations. Hence, the mean and variance of the time series signal (fluctuations) of the particles velocity were measured using optical probe for both the reference case and the case of similar radial profile of gas holdup. Figure 11 shows the time series signal of particles velocity. The reference case has a mean of 3.3 and variance of 0.31 . However, the case of similar radial profile of gas holdup has a mean of 2.31 and variance of 1.3. Since the value of the mean of the signal for the case of similar radial profile of gas holdup is smaller and the value of the variance is larger compared to that of the reference case, the particles velocity of the case of similar radial profile of gas holdup is smaller as shown in Figure 6.

The difference in the magnitudes of the particles velocity profiles between the reference case and the case of non-similar radial profile of gas holdup was less compared to that between 
the reference case and the case of similar radial profile of gas holdup. The case of non-similar radial profile of gas holdup uses glass beads $\left(2450 \mathrm{Kg} / \mathrm{m}^{3}\right)$ as the solids phase similar to that of the reference case. The cross-sectional area of the spout region is much lesser compared to that of the reference case and to the case of similar radial profile of gas holdup, gas velocity is larger compared to the case of similar radial profile of gas holdup and the solids holdup is smaller compared to that of the reference case and the case of similar radial profile of gas holdup. Hence, the cross-sectional area of the solids to flow in the case of non-similar radial profile of gas holdup is much lesser compared to that of the reference case and the case of similar radial profile of gas holdup. The drag force in the case of non-similar radial profile of gas holdup acting on the particles in the spout region was found to be much lesser compared to the other two beds (Figure 10.a and b). The mean and variance of the time series signal (fluctuations) of the particles velocity for the case of non-similar radial profile of gas holdup were found to be 1.72 and 0.98 , respectively (Figure 12). The mean and variance of the time series signal of the particles velocity are smaller compared to that of the reference case and hence, the particles velocity is smaller. Since, both cases of similar and non-similar radial profiles of gas holdup use different solids (steel shots versus glass beads), different gas velocities $(0.64 \mathrm{~m} / \mathrm{s}$ versus $0.74 \mathrm{~m} / \mathrm{s})$, same bed height and different gas density (higher pressure versus atmospheric pressure, Table 1), the drag forces acting on the particles are different (Figure 10), which is smaller in the case of non-similar radial profile of the gas holdup. However, the spout diameter in the case of non-similar radial profile of gas holdup is smaller than that of the case of similar radial profile of gas holdup and hence, the cross-sectional area of the solids to flow is smaller in the former case as mentioned earlier. All these cause the mean and variance of the time series signal of the particles velocity of 
the case of non-similar radial profile of the gas holdup to be smaller than those of the case of similar radial profile of gas holdup. Since higher fluctuations encountered in the velocity measurements in the case of similar radial profile of the gas holdup, the particles velocity of this case is expected to be smaller than that of the case of non-similar radial profile of the gas holdup. This is supported by the measurements of particles velocity demonstrated in Figures 6 and 7. Spouted bed system is a highly non-linear system and hence, more detailed investigation into the difference in particles velocity profiles when the gas or solids holdup profiles are similar and non-similar, needs to be further assessed using CFD and advanced measurement techniques like radioactive particle tracking (RPT), which will be able to provide more insight.

Minimum spouting velocity $\left(\mathrm{U}_{\mathrm{ms}}\right)$ was used for dimensionless representation of the particles velocity for both cases. Different values of $U_{m s}$ have been found in the studied spouted beds and reported in Table 2 due to different conditions used (Table 1). It was observed that there was very little or less difference in dimensionless solids velocities (Figures 8) between the reference case and the case of similar radial profiles of gas holdup. But, for the case of nonsimilar radial profiles of gas holdup, the difference in dimensionless solids velocities with respect to the reference case increases (Figures 9) and the deviation were found to be much more than that observed when the particles velocity profiles in $\mathrm{m} / \mathrm{s}$ were compared.

Therefore, minimum spouting velocity $\left(\mathrm{U}_{\mathrm{ms}}\right)$ becomes an important parameter because of the closeness obtained between the profiles of the reference case and the case of similar radial profiles of gas holdup. Based on this, $\mathrm{U} / \mathrm{U}_{\mathrm{ms}}$ ratio can be used as a scaling parameter to estimate the particles velocity profiles in $\mathrm{m} / \mathrm{s}$ in different spouted beds using the measured or computed dimensionless particles velocity profiles of a reference case provided that they have similar or 
closer gas holdup radial profiles. This confirms the similarity in the hydrodynamics between various spouted beds using the proposed new scale-up methodology.

\subsection{Pressure Fluctuations}

The pressure fluctuations were measured using pressure transducers mentioned earlier. In the present study, the pressure transducers were attached at z/D levels of 1.1, 1.8 and 2.5 for all spouted beds. The signals were analyzed by calculating their mean and variance. The signals from $0.152 \mathrm{~m}$ and $0.076 \mathrm{~m}$ spouted beds were compared at z/D 1.1 (Figure 13).

The mean and variance for $0.152 \mathrm{~m}$ spouted bed were 0.43 and 0.040 , respectively. The mean and variance for $0.076 \mathrm{~m}$ spouted bed at z/D 1.1 were 0.396 and 0.034 , respectively (\% deviation was 14.58\%). The comparison shows that the fluctuations in the two beds are close where the flow dynamics are also close. The fluctuations analyzed for the levels z/D 1.8 and 2.5 are shown in Figures 14 and 15, respectively. At z/D 1.8 the mean of the pressure fluctuation for $0.152 \mathrm{~m}$ and $0.076 \mathrm{~m}$ spouted beds were 0.418 and 0.389 , respectively. The variance was 0.040 in $0.152 \mathrm{~m}$ spouted bed and 0.0291 in $0.076 \mathrm{~m}$ spouted bed (\% deviation was $13.72 \%$ ). The comparison between the two beds at this level also showed closeness in pressure fluctuation profiles for the case of similar radial profile of gas holdup with the reference case (Case A). The nature of the signals also explains the behavior of the bed. The similarity in the magnitude and frequency of the fluctuations in $0.076 \mathrm{~m}$ and $0.152 \mathrm{~m}$ spouted is obvious from the nature of the 
fluctuations. In the fountain region (z/D level 2.5), the pressure fluctuations were also close. The mean for $0.152 \mathrm{~m}$ and $0.076 \mathrm{~m}$ spouted bed was 0.269 and 0.258 , respectively. The variance for $0.152 \mathrm{~m}$ and $0.076 \mathrm{~m}$ spouted bed was found to be 0.029 and 0.025 , respectively (\% deviation was $13.73 \%$ ). This is because the fountain region disengages the solids from the gas phase where the solids fall back onto the bed surface due to gravity and solids volume fraction in this region is close between the cases of similar radial profile of the gas holdup and the reference case. The analysis of the case for the non-similar radial profile of the gas holdup yield larger differences in the fluctuations and accounted for an absolute relative difference of $29.1 \%$.

The overall bed pressure drop was also measured using the pressure transducer by taking readings before the gas inlet and at the outlet of the spouted bed. In order to compare the profiles, they were dimensionalized by dividing the pressure values at each measurement plane by the overall pressure drop of the bed. Figure 16 shows the axial profiles, which shows that the cases for similar radial profile of gas holdup has a close profile to the reference case and the absolute relative difference is $13.4 \%$. For the case of non-similar radial profile of gas holdup the difference is $26.4 \%$.

\subsection{Spout Diameter, Fountain Height and Maximum Spoutable Bed Height.}

Global parameters such as dimensionless fountain height, dimensionless spout diameter, and maximum spoutable bed height were measured for the conditions of similar and non-similar radial profile of gas holdup with respect to the reference Case A. The spout diameters (Ds) were measured using the optical fiber probe (Figure 17). The probe works based on the back reflection 
of the light, and the reflection of the light is dependent on the number of particles in front of the probe. Since there is a large or significant difference in the degree of solids in spout and annulus, distinct signals are obtained in these zones. The probe is first placed in the center of the bed and slowly moved towards the wall. The point where there is a distinct change in the signal that point is marked and the distance was noted. Fountain height (HF) is the maximum height of solids achieved in the spouted bed. The initial bed height is marked and then when the spouted bed is operated under the conditions of the experimentation, the maximum height reached by them is noted. Thus fountain height is measured. Maximum spoutable bed height $(\mathrm{Hm})$ refers to the maximum amount of solids that a bed can accommodate beyond which the spouting does not occur. It can also be termed as the amount of solids the spouted bed can process at a time. To measure this, the initial bed height of spouted bed was increased very gradually in small increments until the spouting in bed did not occur. The bed height at that point was noted to be the maximum spoutable bed height.

All the above parameters were also in close agreement with each other for the condition of similar radial profile of the gas holdup. For the conditions of non-similar radial profile of the gas holdup the deviations were found too large. Table 3 gives the detail list of the dimensionless parameters and their corresponding deviations with the reference case.

\section{REMARKS}

The local and global parameters for the two spouted beds using the cases of similar and non-similar radial profile of gas holdup with respect to the reference case has been measured and 
analyzed. It was confirmed that when the radial profiles of the gas holdup in the two spouted beds were maintained close using the newly identified conditions of similar radial profile of gas holdup, the similarity in the local and global hydrodynamic parameters has been achieved. However, when there is a non-similar radial profiles of the gas holdup in the two beds, the hydrodynamics are different even if there is a geometrical similarity of the compared spouted beds. Accordingly, the new proposed mechanistic scale-up methodology that is based on "The radial profile of the gas holdup should be the same or close for the two spouted beds particularly in the spout region to be both of them hydrodynamically similar or close", has been validated and confirmed at the conditions and dimensions studied in this work.

The magnitudes of the particles velocity profiles for both cases were not similar. However, when the particles velocities were non-dimensionalized and are represented by $U / \mathrm{U}_{\mathrm{ms}}$ the velocity profiles were close for cases of similar radial profiles of the gas holdup and are different with larger deviations for the cases of non-similar radial profiles of the gas holdup. Based on this, $U / U_{m s}$ ratio can be used as a scaling parameter to estimate the magnitudes of the velocity profiles in different spouted beds, provided that the magnitudes of the particles velocity of the reference case are known when the radial profiles of the gas holdup are maintained similar or closer between the two different gas-solid spouted beds. The dimensionless groups approach of He et al. [1] is based on maintaining the same values of different dimensionless groups in the two different spouted beds, poses a practical challenge, since it is very hard to match all the dimensionless groups experimentally in different spouted beds. In addition, such approach found to be not valid with respect to the local parameters as it has been demonstrated by [3] and [8]. Since there are many correlations available in open literature to predict $U_{m s}$ depending on the 
spouted bed geometry, the magnitudes of the particles velocity profiles can be determined using the $\mathrm{U} / \mathrm{U}_{\mathrm{ms}}$ scaling parameter and thereby estimating the scaled-up spouted bed hydrodynamics.

The new proposed methodology with the aid of the advanced techniques and validated CFD simulations can be successfully applied on various scales and conditions of gas-solid spouted beds. The development of the current new mechanistic scale-up methodology can be extrapolated to scale-up other sizes and conditions of gas-solid spouted bed including the industrial sizes and conditions. The implementation of this new methodology that is outlined earlier can be utilized for scaling up to industrial gas-solid spouted beds to ensure their efficiency, economics, safety and optimized energy consumption.

\section{Acknowledgement:}

The authors would like to thank Department of Energy - Nuclear Energy Research Initiative (DOE-NERI) grant (NERI DEFC07-07ID14822) for the financial support, which made this work possible. Also, great thank to the multiphase reactors engineering and applications laboratory (m-Real) for funding and support.

\section{Nomenclature}

U superficial gas velocity $(\mathrm{m} / \mathrm{s})$

$\mathrm{D}_{\mathrm{c}} \quad$ column diameter $(\mathrm{m})$

$\mathrm{D}_{\mathrm{s}} \quad$ spout diameter $(\mathrm{m})$

$\mathrm{D}_{\mathrm{i}} \quad$ gas inlet diameter $(\mathrm{m})$

g gravitational acceleration $\left(\mathrm{kg} / \mathrm{m}^{2}\right)$ 
$d_{p} \quad$ particle diameter $(\mu \mathrm{m})$

$\mathrm{H} \quad$ static bed height (m)

$\mathrm{H}_{\mathrm{m}} \quad$ maximum spoutable bed height (m)

$\mathrm{U}_{\mathrm{ms}} \quad$ minimum spouting velocity $(\mathrm{m} / \mathrm{s})$

$\mathrm{r} \quad$ point of measurement (m)

$\mathrm{R}$ radial distance $(\mathrm{m})$

$\mathrm{Z} \quad$ axial point of measurement (m)

\section{Greek symbols}

$\varepsilon \quad$ volume fraction or holdup

$\rho_{s} \quad$ particle density $\left(\mathrm{kg} / \mathrm{m}^{3}\right)$

$\rho_{f} \quad$ fluid density $\left(\mathrm{kg} / \mathrm{m}^{3}\right)$

$\mu \quad$ viscosity (Pa s)

$\phi_{s} \quad$ sphericity of particles

$\varphi \quad$ interfacial angle of particle

\section{Subscripts}

S solids

f fluid (gas)

P particle

\section{References:}

1- He, Y-L., C. J. Lim, and J. R. Grace. "Scale-up studies of spouted beds." Chemical Engineering Science 52, no. 2 (1997): 329-339.

2- Glicksman, L. R. (1984). Scaling relationships for fluidized beds. Chemical engineering science, 39(9), 1373-1379. 
3- Aradhya S., Taofeeq H. and Al-Dahhan M., Invalidation of the Dimensionless Groups Based Scale-Up of Gas-Solid Spouted Beds. Submitted to the international journal of multiphase flow.

4- Ali, N., Al-Juwaya, T., \& Al-Dahhan, M. (2016). Demonstrating the non-similarity in local holdups of spouted beds obtained by CT with scale-up methodology based on dimensionless groups. Chemical Engineering Research and Design.

5- Matthew, M. C., Morgan, M. H., \& Littman, H. (1988). Study of the hydrodynamics within a draft tube spouted bed system. The Canadian Journal of Chemical Engineering, 66(6), 908-918.

6- Kalwar, M. I., Raghavan, G. S. V., \& Mujumdar, A. S. (1993). Circulation of particles in two-dimensional spouted beds with draft plates. Powder technology, 77(3), 233-242.

7- Zhao, X. L., Li, S. Q., Liu, G. Q., Song, Q., \& Yao, Q. (2008). Flow patterns of solids in a two-dimensional spouted bed with draft plates: PIV measurement and DEM simulations. Powder Technology, 183(1), 79-87.

8- Aradhya, Shreekanta Basavaraj. "Scaleup and hydrodynamics study of gas-solid spouted beds.", PhD Thesis, Missouri University of Science and Technology (2013).

9- Ali, Neven Y. "Evaluating of scale-up methodologies of gas-solid spouted beds for coating triso nuclear fuel particles using advanced measurement techniques.", $\mathrm{PhD}$ Thesis, Missouri University of Science and Technology (2016).

10-Shaikh, Ashfaq, and Muthanna Al-Dahhan. "Scale-up of bubble column reactors: a review of current state-of-the-art." Industrial \& Engineering Chemistry Research 52, no. 24 (2013): 8091-8108. 
11- Al-Dahhan, Muthanna, Shreekanta Aradhya, Faraj Zaid, Neven Ali, and Thaar Aljuwaya. "Scale-up and on-line monitoring of gas-solid systems using advanced and non-invasive measurement techniques." Procedia Engineering 83 (2014): 469-476.

12-Shaikh, Ashfaq, and Muthanna Al-Dahhan. "A new methodology for hydrodynamic similarity in bubble columns." The Canadian Journal of Chemical Engineering 88, no. 4 (2010): 503-517.Y. L.

13-Lan, X., Xu, C., Gao, J., \& Al-Dahhan, M. (2012). Influence of solid-phase wall boundary condition on CFD simulation of spouted beds. Chemical Engineering Science, 69(1), 419-430.

14- Mathur, K. B_, and P. E. Gishler. "A technique for contacting gases with coarse solid particles." AIChE Journal 1, no. 2 (1955): 157-164.

15-Xu, Jian, Xiaojun Bao, Weisheng Wei, Gang Shi, Shikong Shen, H. T. Bi, J. R. Grace, and C. J. Lim. "Statistical and frequency analysis of pressure fluctuations in spouted beds." Powder Technology 140, no. 1 (2004): 141-154. 
List of Figures 

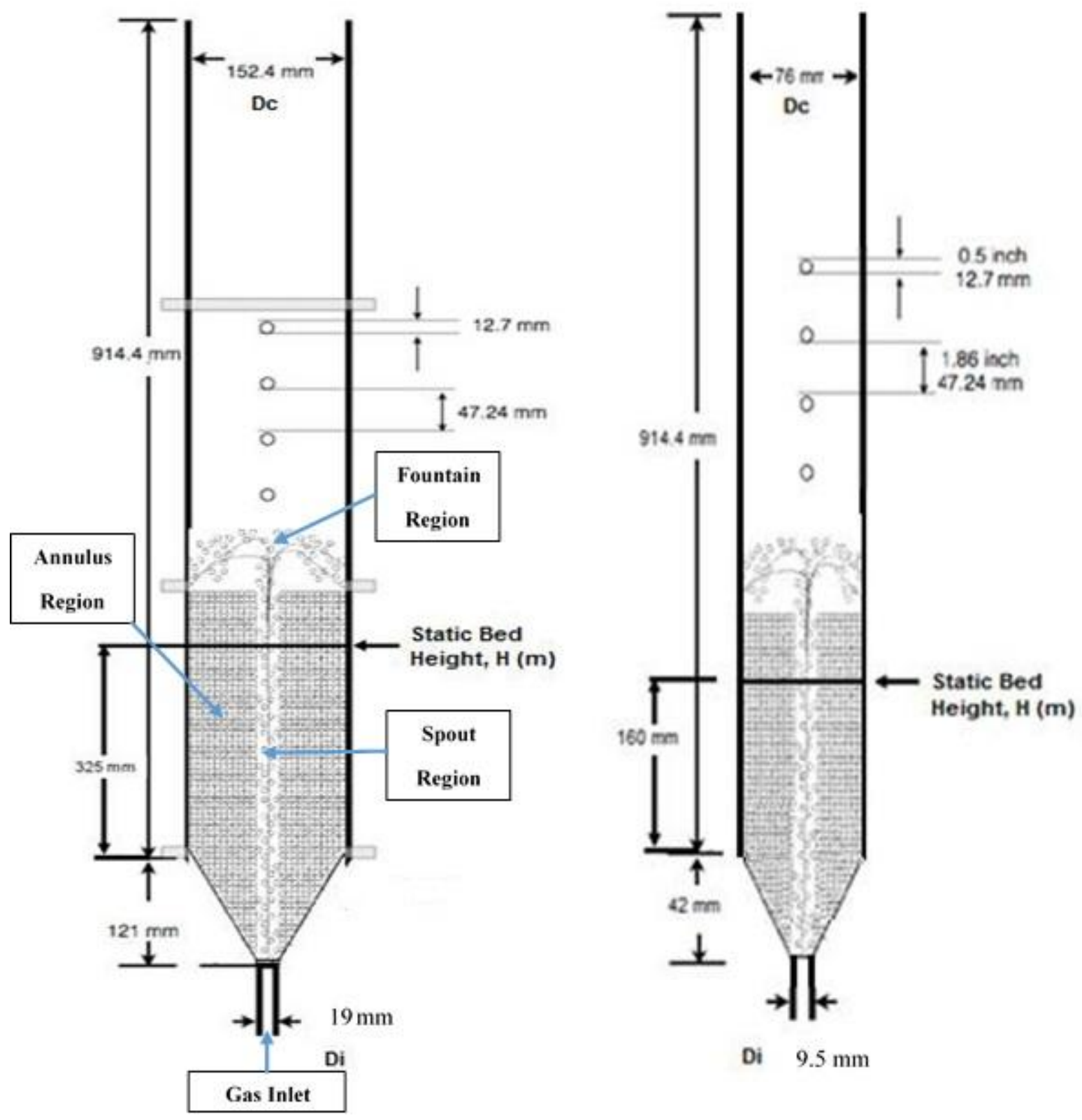

Figure 1. Schematic of spouted beds and detailed dimensions of $0.152 \mathrm{~m}$ and $0.076 \mathrm{~m}$ spouted beds used in the present work. 


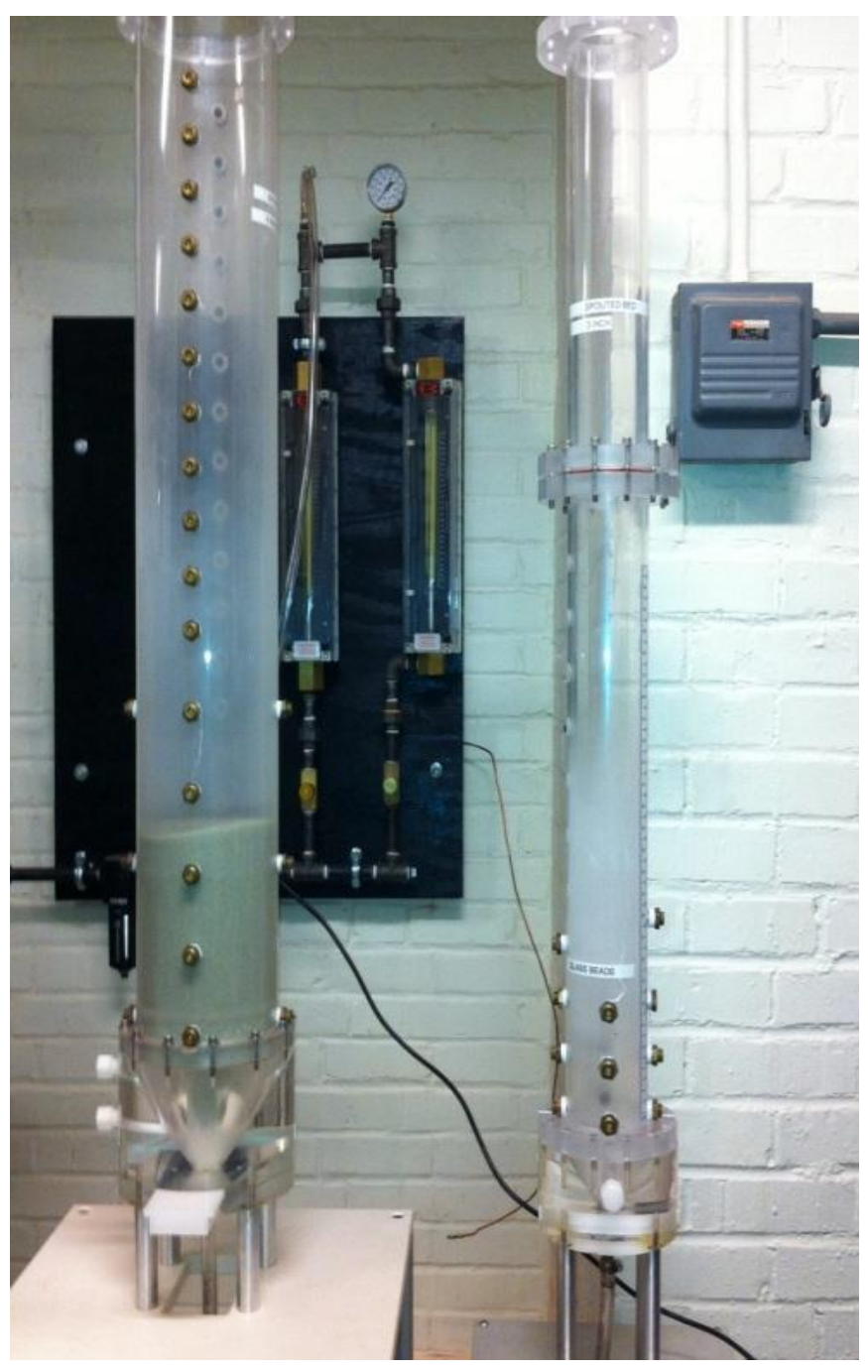

Figure $1 \mathrm{~b}$. Photograph of the $0.152 \mathrm{~m}$ and $0.076 \mathrm{~m}$ spouted bed used in the present work. 


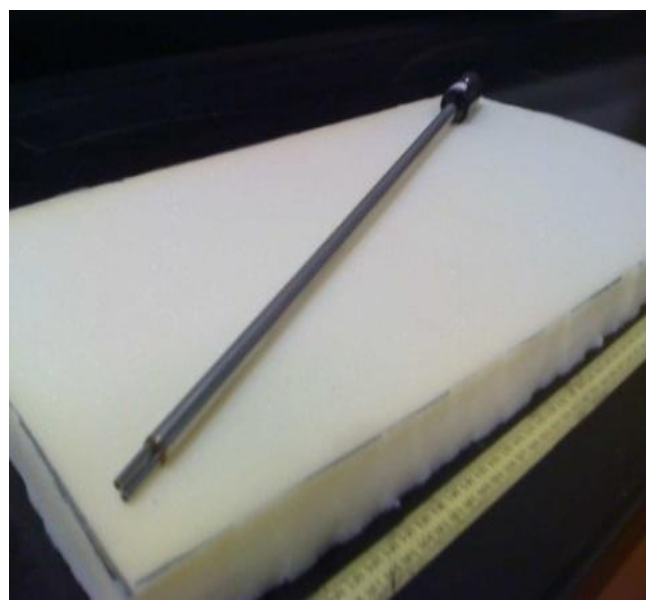

(a)

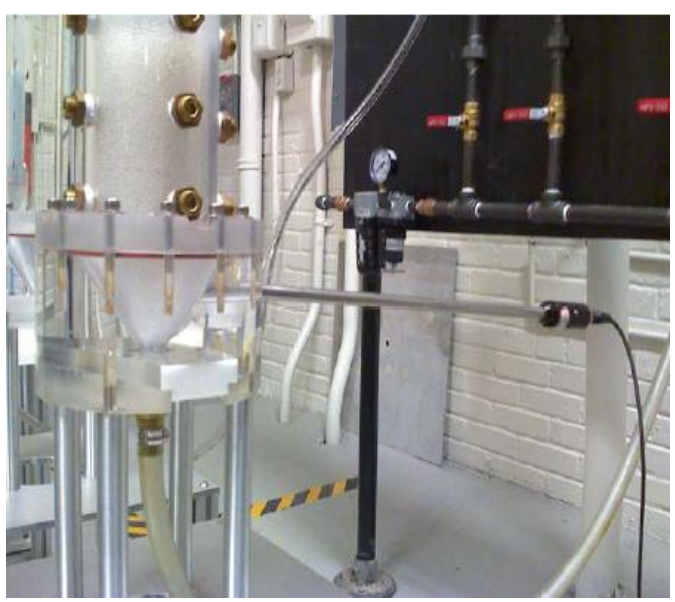

(b)

Figure 2. Gas-solid optical probe (a) Fiber optic probe (PV6) used in the present work; (b) PV6 being used in spouted bed. 


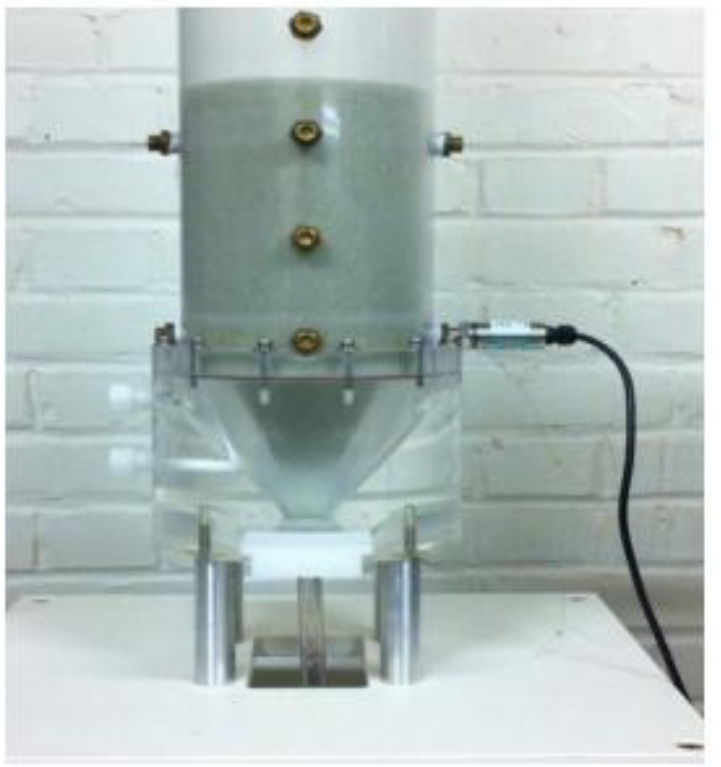

Figure 3. Pressure transducer applied for measurement on $0.152 \mathrm{~m}$ ID spouted bed 

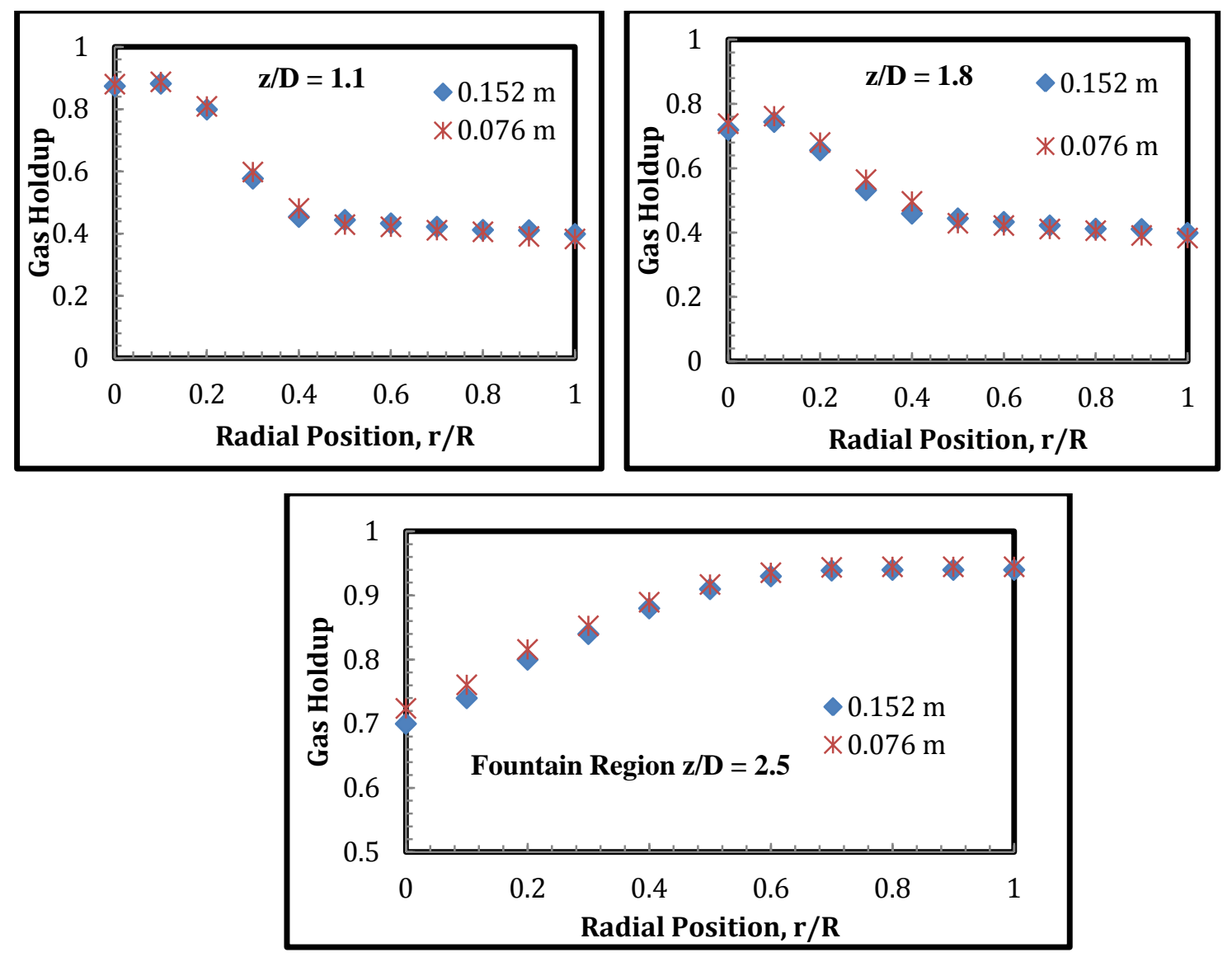

Figure 4. Gas holdup profiles for the conditions for similar radial profile of gas holdup in 0.152 $\mathrm{m}$ and $0.076 \mathrm{~m}$ spouted bed at different $\mathrm{z} / \mathrm{D}$ measurement levels. 

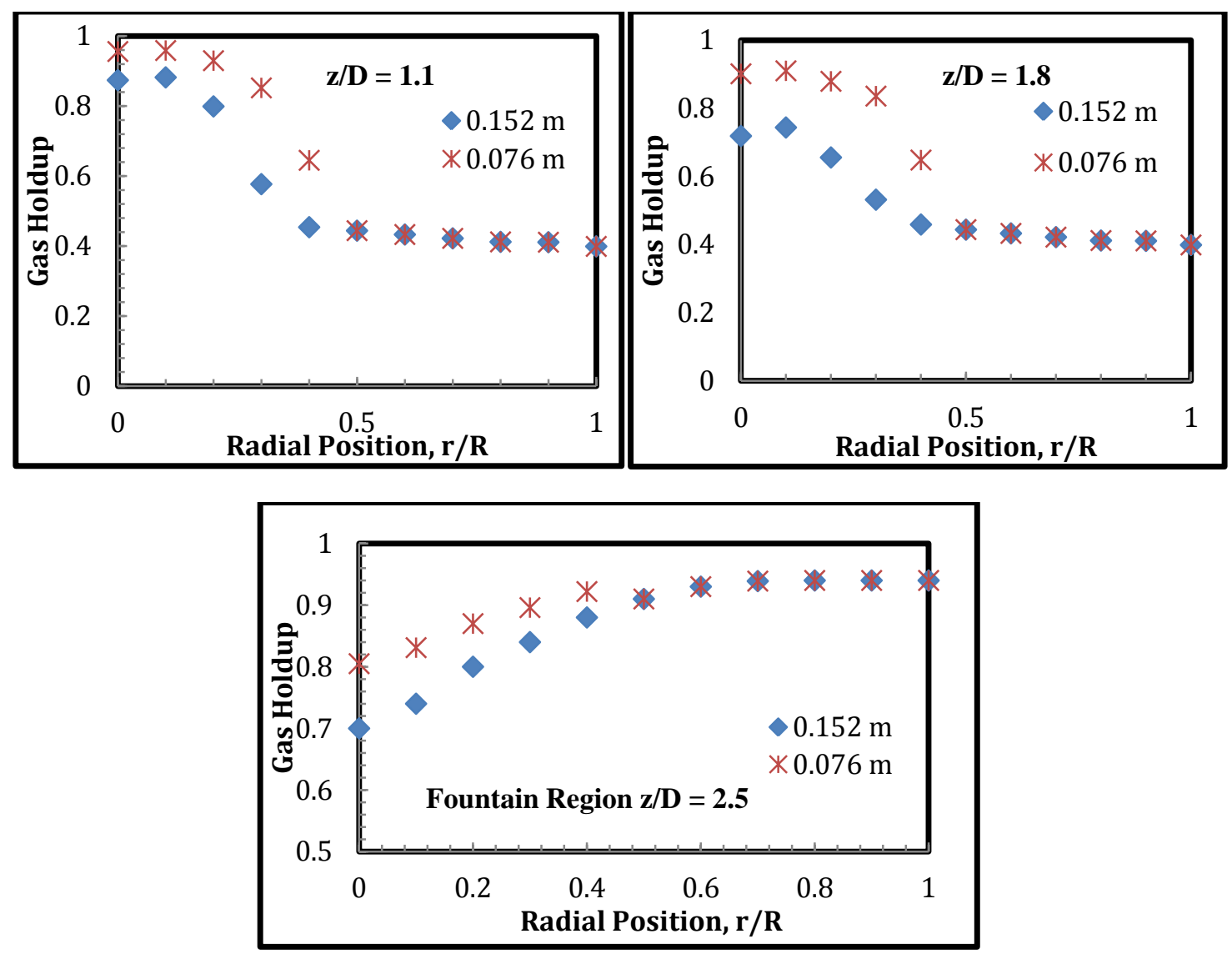

Figure 5. Gas holdup profiles for the conditions for non-similar radial profile of gas holdup in $0.152 \mathrm{~m}$ and $0.076 \mathrm{~m}$ spouted bed at different $\mathrm{z} / \mathrm{D}$ measurement levels. 

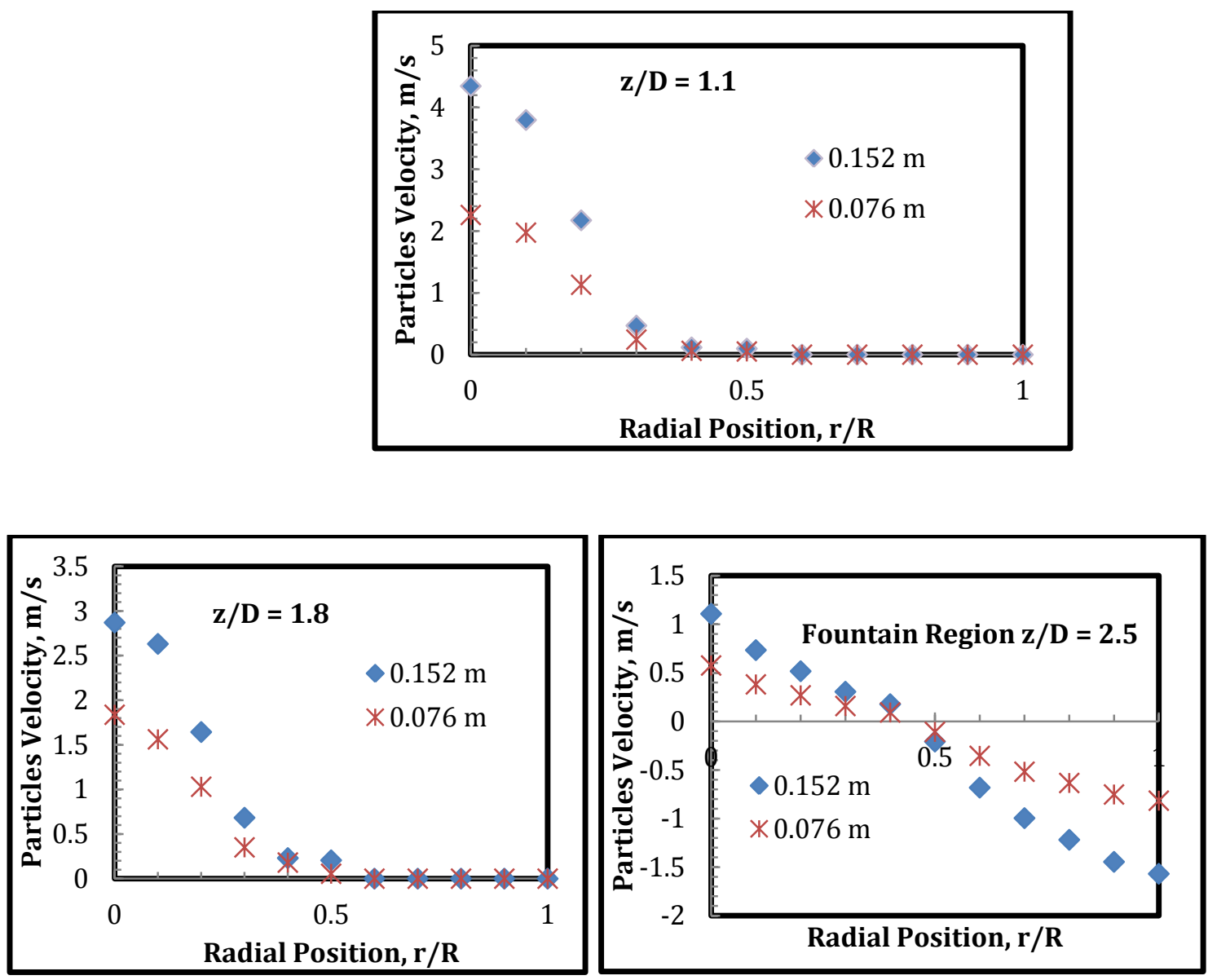

Figure 6. Particles velocity profiles for the conditions for similar radial profile of gas holdup in $0.152 \mathrm{~m}$ and $0.076 \mathrm{~m}$ spouted bed at different $\mathrm{z} / \mathrm{D}$ levels. 

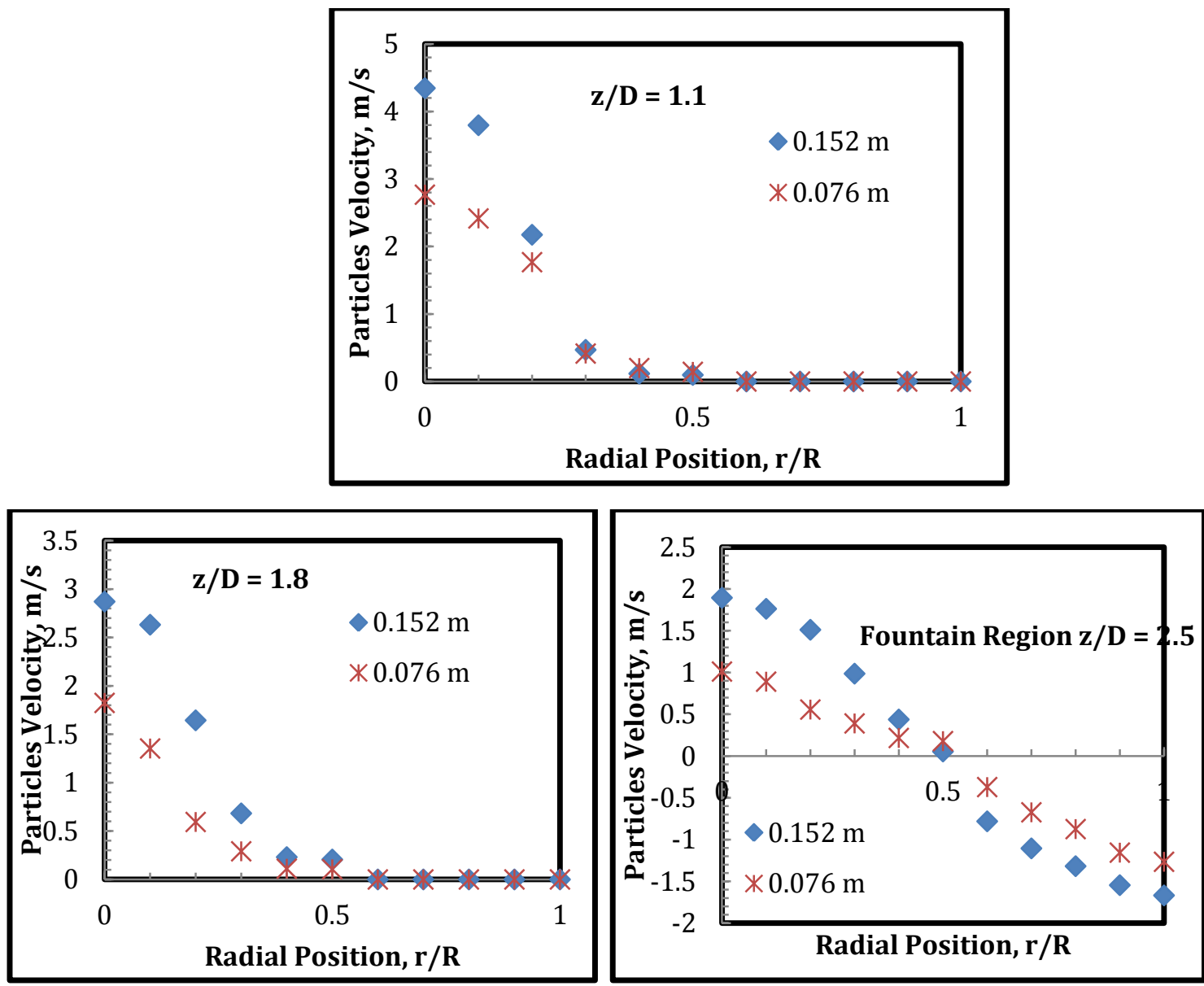

Figure 7. Particles velocity profiles for the conditions for non-similar radial profile of gas holdup in $0.152 \mathrm{~m}$ and $0.076 \mathrm{~m}$ spouted bed at different $\mathrm{z} / \mathrm{D}$ levels. 

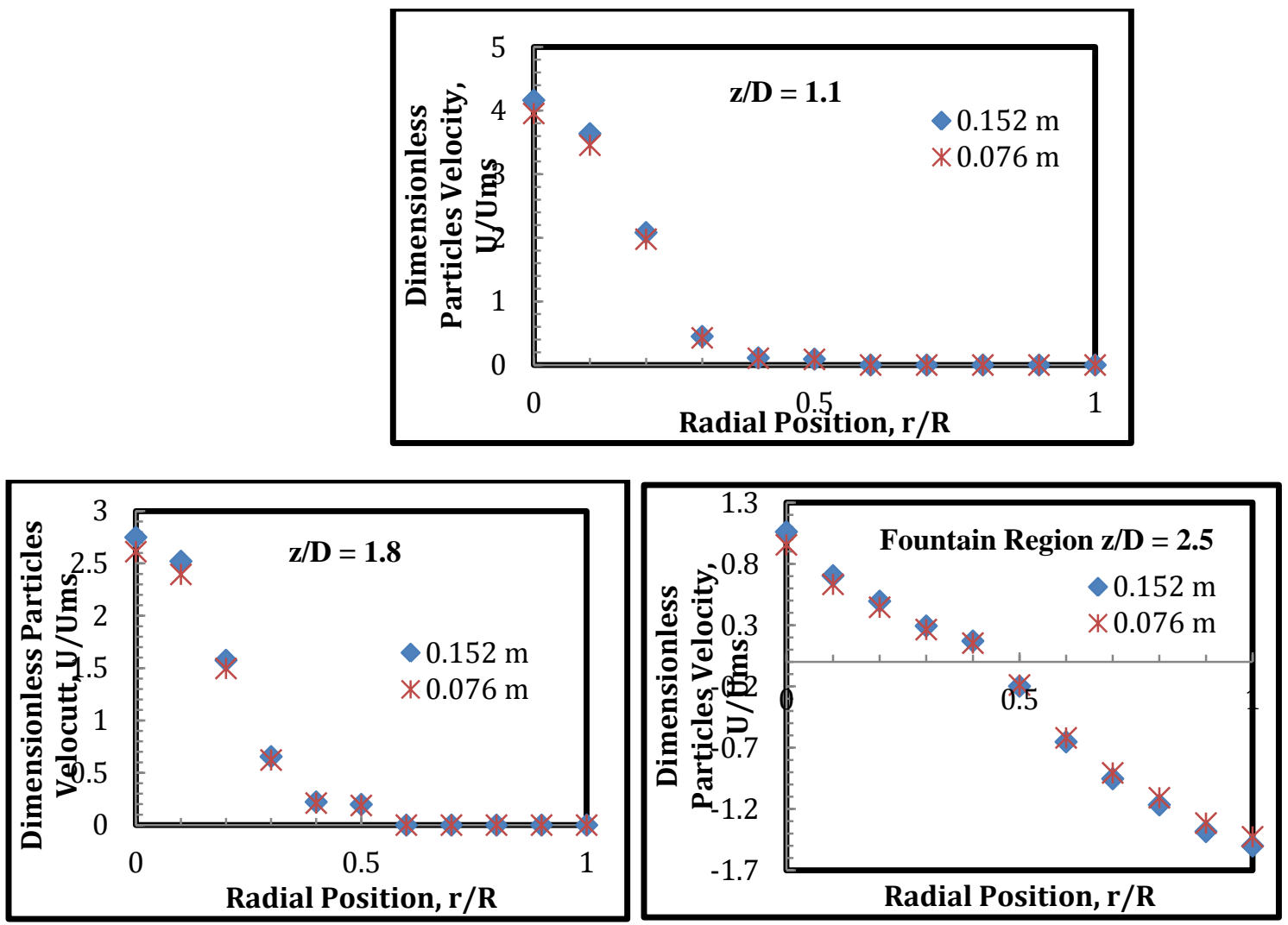

Figure 8. Dimensionless particles velocity profiles for the conditions for similar radial profile of gas holdup in $0.152 \mathrm{~m}$ and $0.076 \mathrm{~m}$ spouted bed at different $\mathrm{z} / \mathrm{D}$ levels. 

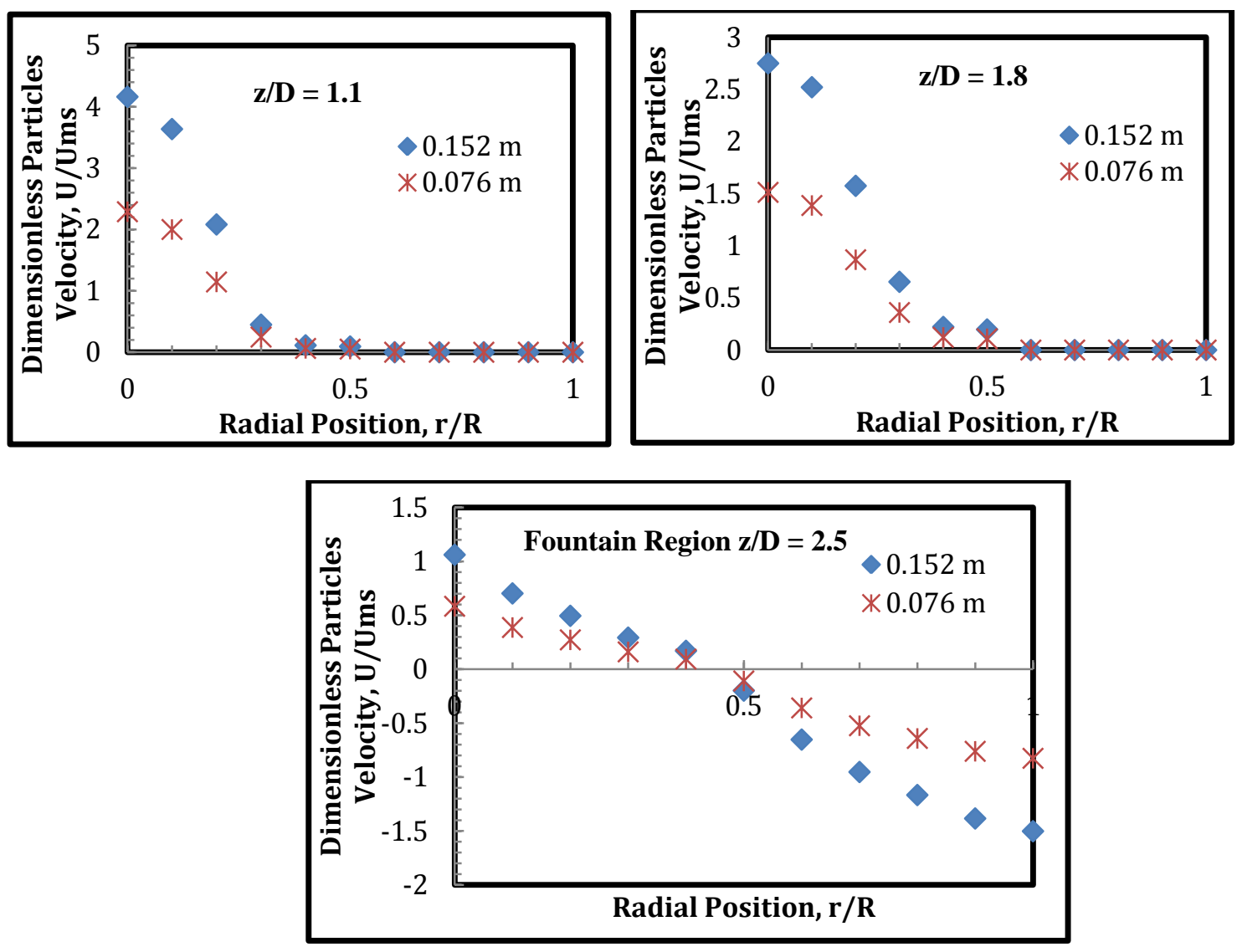

Figure 9. Dimensionless particles velocity profiles for the conditions for non-similar radial profile of gas holdup in $0.152 \mathrm{~m}$ and $0.076 \mathrm{~m}$ spouted bed at different $\mathrm{z} / \mathrm{D}$ levels. 


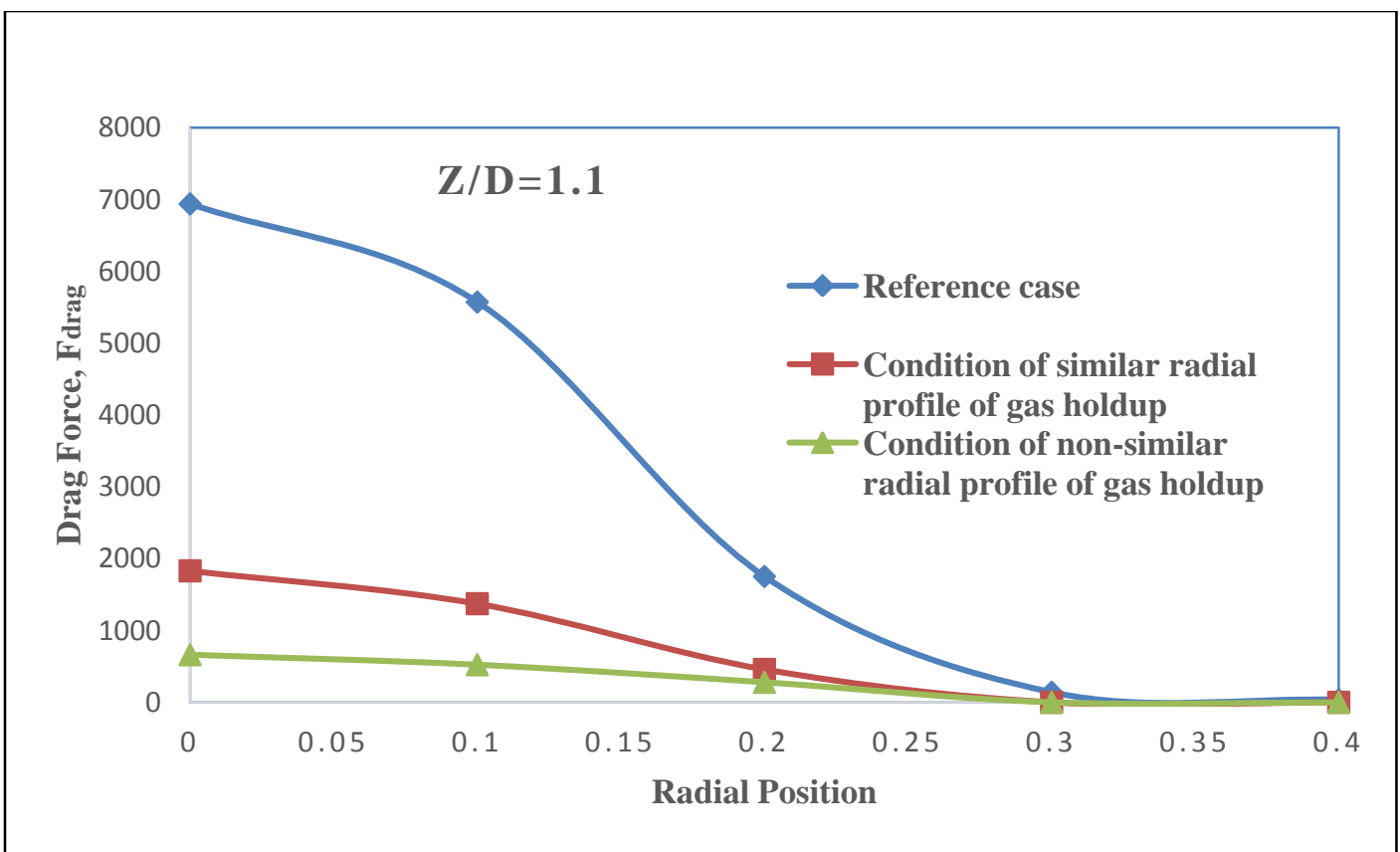

(a)

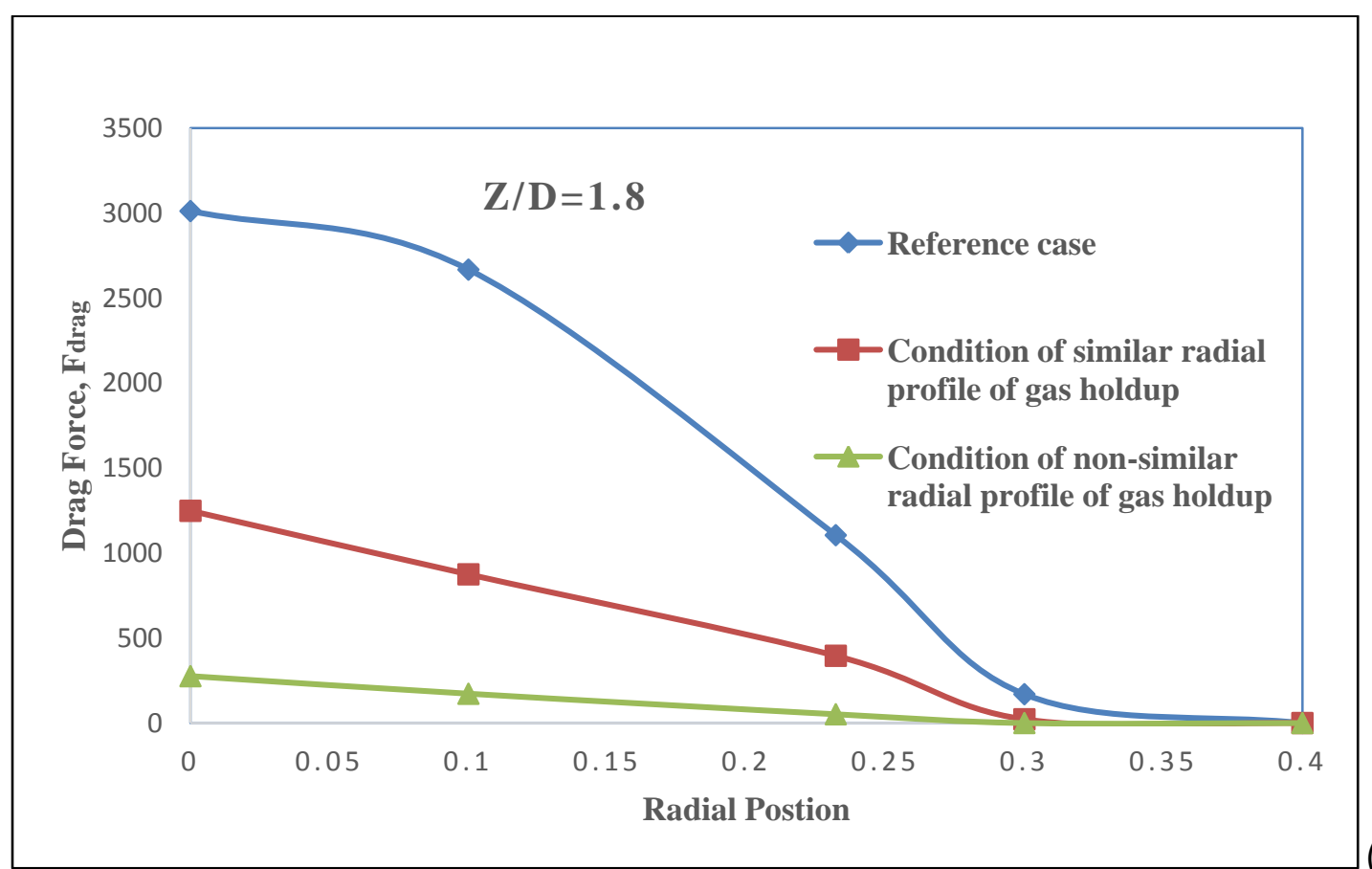

(b)

Figure 10. Drag force in the spout region evaluated from CFD; a. Drag force for reference case, conditions for similar and non-similar radial profiles of gas holdup at $\mathrm{z} / \mathrm{D}=1.1 ; \mathrm{b}$. Drag force for reference case, conditions for similar and non-similar radial profiles of gas holdup at z/D = 1.8. 


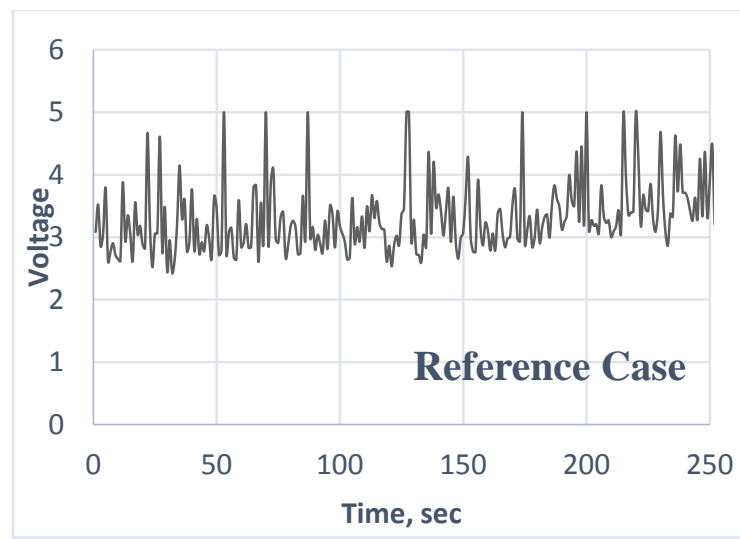

(a)

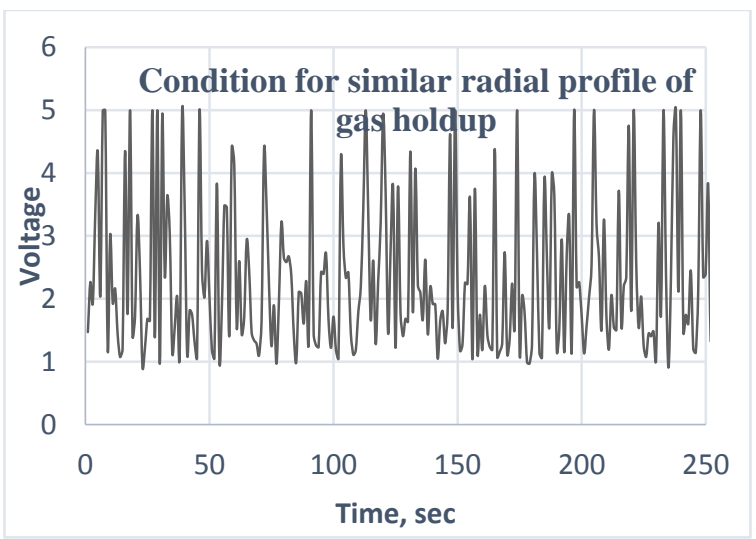

(b)

Figure 11. Time series fluctuations of particles velocity; a. For the reference case at z/D 1.1 with mean $=3.3$ and variance $=0.31 ; \mathrm{b}$. For conditions of similar radial profile of gas holdup at $\mathrm{z} / \mathrm{D}$ 1.1 with mean $=2.31$ and variance $=1.3$. 


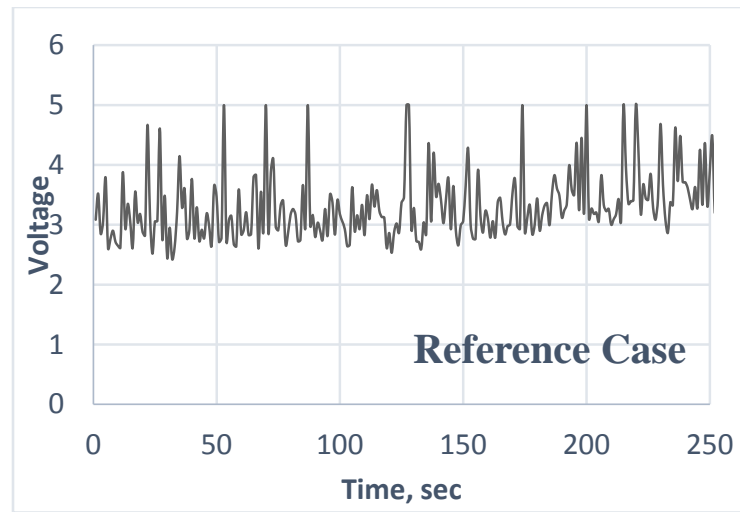

(a)

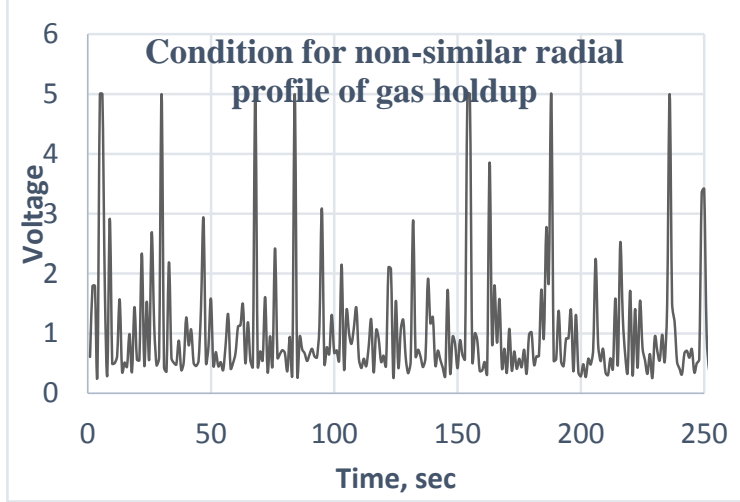

(b)

Figure 12. Time series fluctuations of particles velocity; a. For the reference case at z/D 1.1 with mean $=3.3$ and variance $=0.31 ; b$. For conditions of non-similar radial profile of gas holdup at $\mathrm{z} / \mathrm{D} 1.1$ with mean $=1.72$ and variance $=0.98$. 

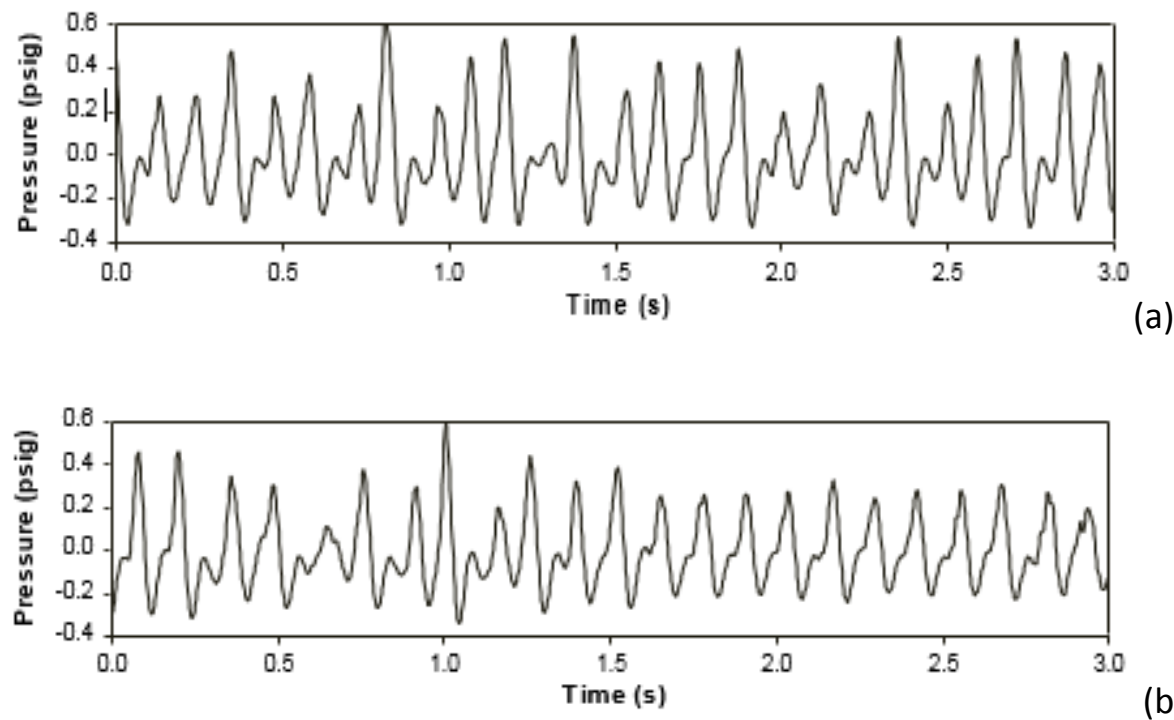

(b)

Figure 13. Gauge pressure fluctuations; a. Pressure fluctuation signals in $0.152 \mathrm{~m}$ spouted bed at $\mathrm{z} / \mathrm{D}=1.1 ; \mathrm{b}$. Pressure fluctuation signals in $0.076 \mathrm{~m}$ spouted bed at $\mathrm{z} / \mathrm{D}=1.1$ 


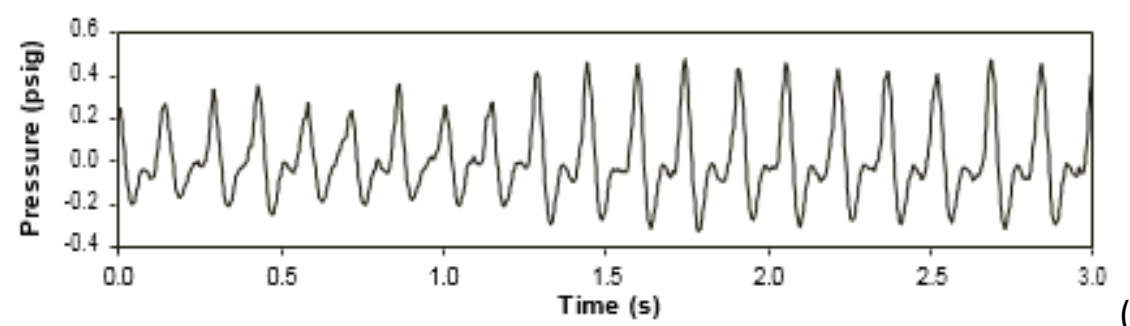

(a)

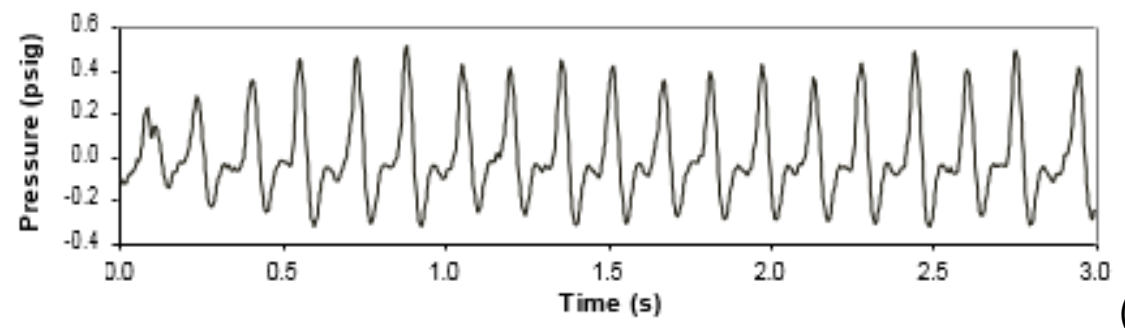

(b)

Figure 14. Gauge pressure fluctuations; a. Pressure fluctuation signals in $0.152 \mathrm{~m}$ spouted bed at $\mathrm{z} / \mathrm{D}=1.8 ; \mathrm{b}$. Pressure fluctuation signals in $0.076 \mathrm{~m}$ spouted bed at $\mathrm{z} / \mathrm{D}=1.8$. 


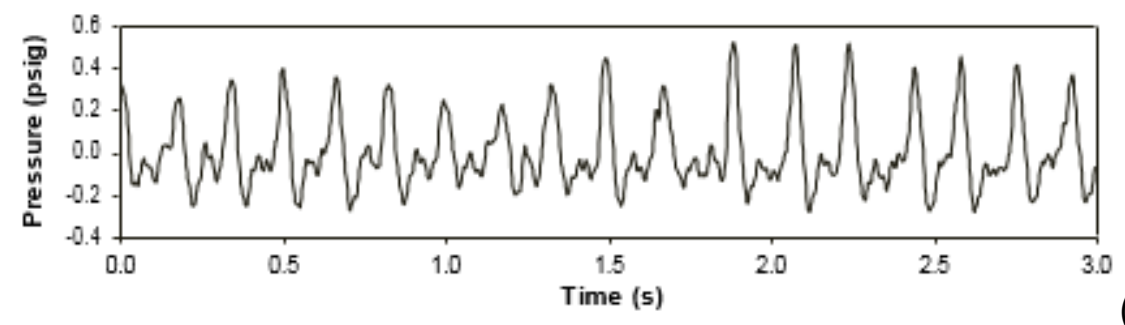

(a)

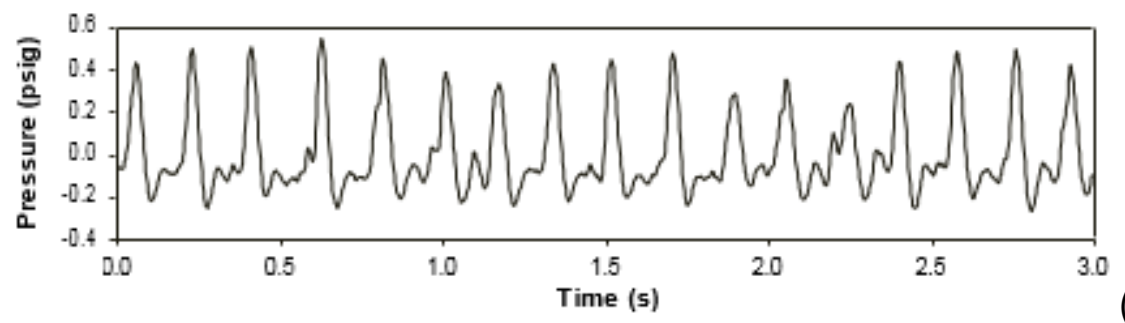

Figure 15. Gauge pressure fluctuations; a. Pressure fluctuation signals in $0.152 \mathrm{~m}$ spouted bed at $\mathrm{z} / \mathrm{D}=2.5 ; \mathrm{b}$. Pressure fluctuation signals in $0.076 \mathrm{~m}$ spouted bed at $\mathrm{z} / \mathrm{D}=2.5$ 


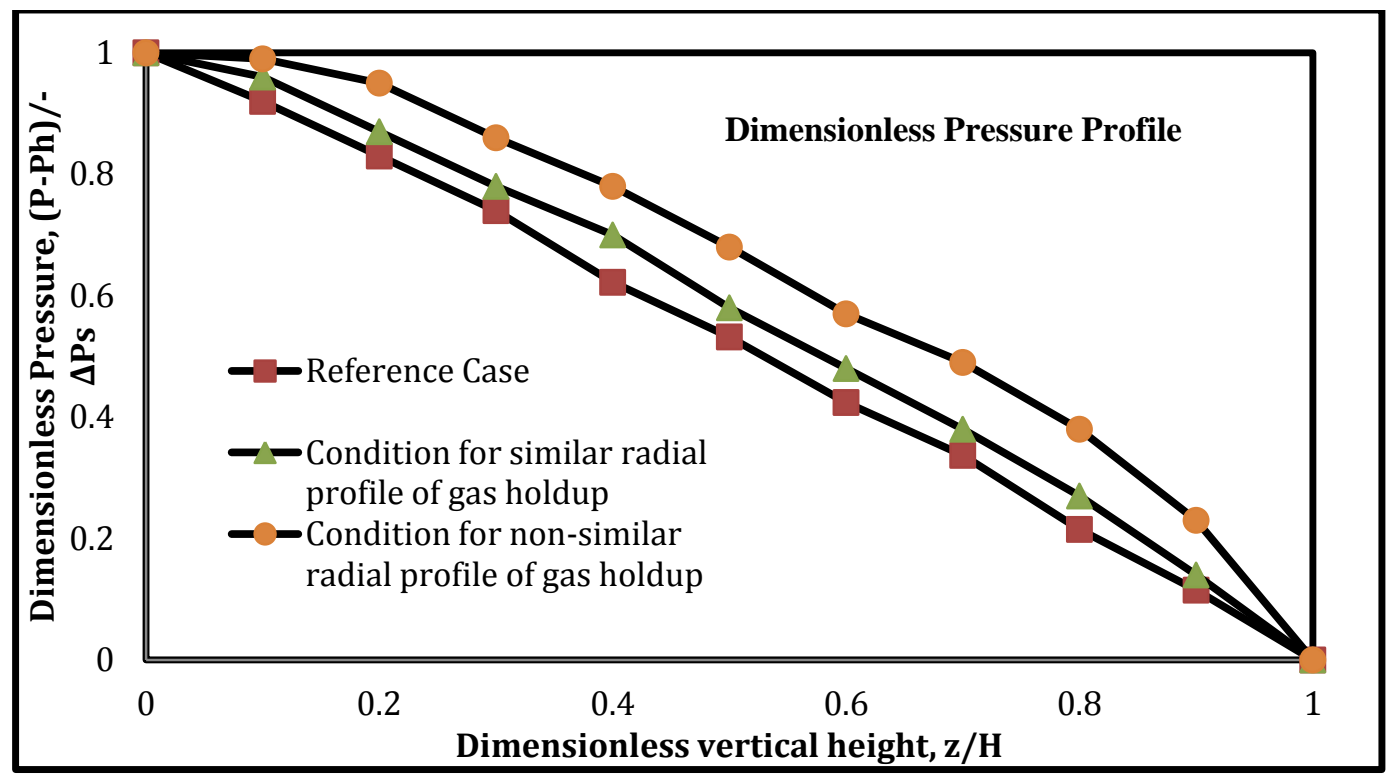

Figure 16. Dimensionless pressure profile for the conditions of similar and non-similar radial profiles of gas holdup measured experimentally using pressure transducers. 


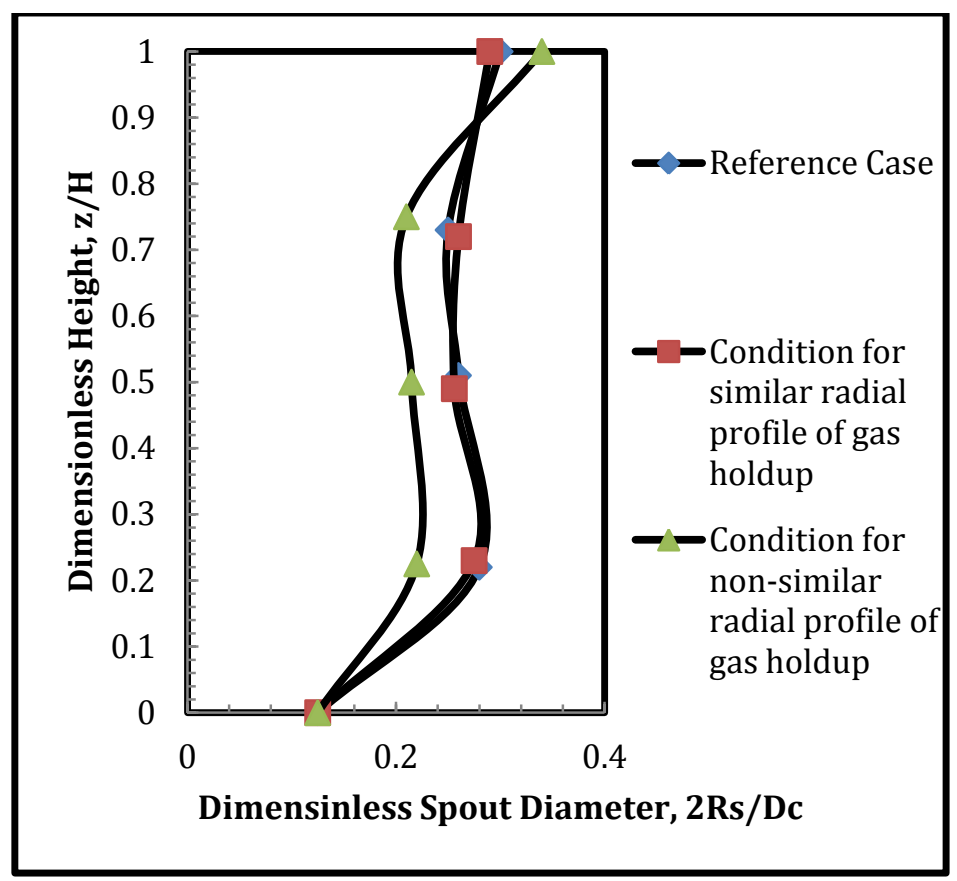

Figure 17. Dimensionless spout diameter versus dimensionless height. 


\section{List of Tables}

Table 1 Conditions for similar and non-similar gas holdup radial profiles $\left(\varepsilon_{\mathrm{g}}\right)_{\mathrm{r}}$ for the hydrodynamics similarity approach.

\begin{tabular}{|c|c|c|c|}
\hline Case & $\begin{array}{l}\text { Reference } \\
\text { Case } \\
\text { (Case A) }\end{array}$ & $\begin{array}{c}\text { Conditions } \\
\text { For Similar }\left(\varepsilon_{\mathrm{g}}\right)_{\mathrm{r}}\end{array}$ & $\begin{array}{c}\text { Conditions } \\
\text { For Non-Similar } \\
\left(\varepsilon_{\mathrm{g}}\right)_{\mathrm{r}}\end{array}$ \\
\hline $\mathbf{D}_{\mathbf{c}}(\mathbf{m})$ & 0.152 & 0.076 & 0.076 \\
\hline $\mathbf{D}_{\mathbf{i}}(\mathbf{m})$ & 0.019 & 0.0095 & 0.0095 \\
\hline $\mathbf{L}(\mathbf{m})$ & 1.14 & 1.14 & 1.14 \\
\hline $\mathbf{H}(\mathbf{m})$ & 0.323 & 0.16 & 0.16 \\
\hline $\mathbf{T}(\mathbf{K})$ & 298 & 298 & 298 \\
\hline $\mathbf{P}(\mathbf{k P a})$ & 101 & 364 & 101 \\
\hline Particles & Glass Beads & Steel & Glass Beads \\
\hline$d_{p}(m)$ & 0.00218 & 0.00109 & 0.00109 \\
\hline$\rho_{p}\left(K g / m^{3}\right)$ & 2450 & 7400 & 2450 \\
\hline$\rho_{\mathrm{f}}\left(\mathrm{Kg} / \mathbf{m}^{3}\right)$ & 1.21 & 3.71 & 1.21 \\
\hline$\mu\left(* 10^{-5}\right)($ Pa. $s)$ & 1.81 & 1.81 & 1.81 \\
\hline $\mathbf{U}(\mathbf{m} / \mathbf{s})$ & 1.08 & 0.64 & 0.74 \\
\hline $\mathbf{U}_{\mathrm{ms}}(\mathbf{m} / \mathbf{s})$ & 1.04 & 0.69 & 0.52 \\
\hline $\mathrm{H} / \mathbf{D}_{\mathrm{c}}$ & 2.1 & 2.1 & 2.1 \\
\hline$D_{c} / D_{i}$ & 8 & 8 & 8 \\
\hline$D_{c} / d_{p}$ & 69.9 & 69.9 & 69.9 \\
\hline$\rho_{p} / \rho_{f}$ & 1994 & 1995 & 2029 \\
\hline$\varepsilon_{\mathrm{mf}}$ & 0.41 & 0.42 & 0.42 \\
\hline $\boldsymbol{\rho}_{\mathrm{f}}^{*} \mathbf{d}_{\mathbf{p}} * \mathbf{U} / \boldsymbol{\mu}$ & 157 & 297 & 54 \\
\hline $\mathbf{U}^{2} /\left(\mathbf{g}^{*} \mathbf{d}_{\mathrm{p}}\right)$ & 54.5 & 38.3 & 51.2 \\
\hline$\rho_{\mathbf{p}} * d_{p} * U / \mu$ & 3.13 & 1.39 & 1.09 \\
\hline $\mathbf{U}^{2} /\left(\mathbf{g}^{*} \mathbf{D}_{\mathbf{c}}\right)$ & 0.78 & 0.549 & 0.73 \\
\hline
\end{tabular}


Table 2. Comparison between experimental values and correlations predictions of $U_{\mathrm{ms}}$

\begin{tabular}{|c|c|c|c|}
\hline $\begin{array}{c}\text { Diameter of } \\
\text { Spouted bed }\end{array}$ & $\begin{array}{c}\text { Experimental } \\
\text { Values }\end{array}$ & $\begin{array}{c}\text { Correlation } \\
\text { prediction of Mathur } \\
\text { and Gishler, 1995 [6] }\end{array}$ & $\begin{array}{c}\text { Correlation } \\
\text { prediction of Xu } \\
\text { et al., 2004 [7] }\end{array}$ \\
\hline $\begin{array}{c}\text { Case A } \\
(0.152 \mathrm{~m})\end{array}$ & $1.04 \mathrm{~m} / \mathrm{s}$ & $1.028 \mathrm{~m} / \mathrm{s}$ & $1.035 \mathrm{~m} / \mathrm{s}$ \\
\hline $\begin{array}{c}\text { Case B } \\
(0.076 \mathrm{~m})\end{array}$ & $0.69 \mathrm{~m} / \mathrm{s}$ & $0.675 \mathrm{~m} / \mathrm{s}$ & $0.681 \mathrm{~m} / \mathrm{s}$ \\
\hline
\end{tabular}

Table 3. Dimensionless spout diameter and fountain height for the conditions of similar and nonsimilar radial profile of gas holdup.

\begin{tabular}{|l|c|c|c|}
\hline \multicolumn{1}{|c|}{ Case } & $\begin{array}{c}\text { Reference } \\
\text { Case }\end{array}$ & $\begin{array}{c}\text { Conditions } \\
\text { For Similar } \\
\left(\varepsilon_{\mathrm{g}}\right)_{\mathrm{r}}\end{array}$ & $\begin{array}{c}\text { Conditions } \\
\text { For Non-Similar } \\
\left(\boldsymbol{\varepsilon}_{\mathrm{g}}\right)_{\mathrm{r}}\end{array}$ \\
\hline Column diameter, $\mathrm{D}_{\mathrm{c}}$ & 0.152 & 0.076 & 0.076 \\
\hline Mean Spout diameter, $\mathrm{D}_{\mathrm{s}}$ & 0.045 & 0.024 & 0.0211 \\
\hline Fountain Height, $\mathrm{H}_{\mathrm{F}}$ & 0.135 & 0.059 & 0.044 \\
\hline $\begin{array}{l}\text { Dimensionless Spout diameter, } \\
\mathrm{D}_{\mathrm{s}} / \mathrm{D}_{\mathrm{c}}\end{array}$ & 0.27 & 0.28 & 0.277 \\
\hline Deviation \% & - & +3.5 & +6.5 \\
\hline $\begin{array}{l}\text { Dimensionless Fountain Height, } \\
\mathrm{H}_{\mathrm{f}} / \mathrm{D}_{\mathrm{c}}\end{array}$ & 0.89 & 0.78 & 0.58 \\
\hline Deviation \% & - & -12.3 & -34.8 \\
\hline $\begin{array}{l}\text { Maximum spoutable bed } \\
\text { height, } \mathrm{H}_{\mathrm{m}}\end{array}$ & 396 & 195 & 240 \\
\hline $\mathrm{H}_{\mathrm{m}} / \mathrm{D}_{\mathrm{c}}$ & 2.6 & 2.56 & 3.15 \\
\hline Deviation (\%) & - & -1.5 & -21.2 \\
\hline
\end{tabular}




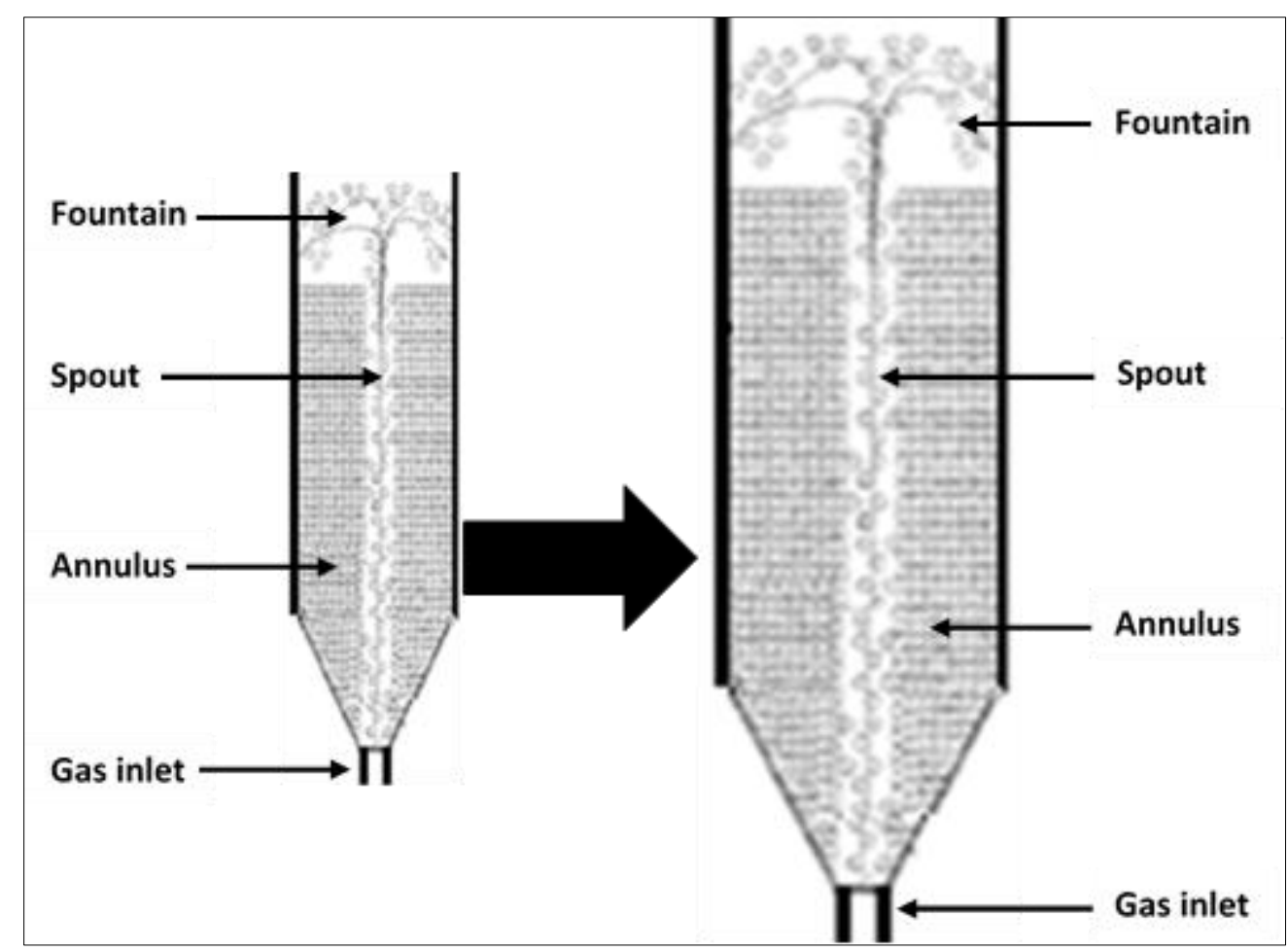

